\title{
MARIANA SIVIERO
}

\section{Avaliação sensitiva orofacial, gustativa, olfativa e salivar em doentes com neuralgias trigeminais}

Dissertação apresentada à Faculdade de Medicina da Universidade de São Paulo para a obtenção do título de Mestre em Ciências

Programa de Neurologia

Orientadora: Profa. Dra. Sílvia Regina

Dowgan Tesseroli de Siqueira

São Paulo

2011 
Dados Internacionais de Catalogação na Publicação (CIP)

Preparada pela Biblioteca da

Faculdade de Medicina da Universidade de São Paulo

Creprodução autorizada pelo autor

\section{Siviero, Mariana}

Avaliação sensitiva orofacial, gustativa, olfativa e salivar em doentes com neuralgias trigeminais / Mariana Siviero. --- São Paulo, 2011.

Dissertação(mestrado)--Faculdade de Medicina da Universidade de São Paulo. Programa de Neuralgia.

Orientadora: Sílvia Regina Dowgan Tesseroli de Siqueira.

Descritores: 1.Neuralgia facial 2.Modalidades sensoriais 3.Limiar sensorial 4.Neuralgia do trigêmeo 5.Neuralgia pós-herpética 6.Síndrome da ardência bucal 7.Dor orofacial

USP/FM/DBD-295/11 


\section{Dedicatória}

Eu dedico este trabalho aos meus pais,

que sempre estiveram ao meu lado. 


\section{Agradecimentos}

A minha orientadora, Dra. Sílvia RDT de Siqueira, por toda paciência e ensinamentos ao longo desses anos;

À minha família, pelo apoio e amor incondicional;

Ao Departamento de Neurologia do Hospital das Clínicas da USP, representado por todos seus funcionários, pela colaboração na confecção desta tese;

Ao Prof. Dr. Manoel Jacobsen Teixeira por todo conhecimento transmitido;

Aos participantes deste estudo, por pacientemente colaborarem comigo no recolhimento dos dados;

E a todos aqueles que colaboraram de forma direta ou indireta para a realização desta pesquisa. 
Esta dissertação está de acordo com as seguintes normas, em vigor no momento desta publicação:

Referências: Adaptado de International Committee of Medical Journals Editors (Vancouver)

Universidade de São Paulo. Faculdade de Medicina. Serviço de Biblioteca e Documentação. Guia de Apresentação de Dissertações, Teses e Monografias. Elaborado por Anneliese Carneiro da Cunha, Maria Julia de A. L. Freddi, Maria F. Crestana, Marinalva de Souza Aragão, Suely Campos Cardoso, Valéria Vilhena. $3^{\mathrm{a}}$ ed. São Paulo: Serviço de Biblioteca e Documentação; 2011.

Abreviaturas dos títulos dos periódicos de acordo com List of Journals Indexed in Index Medicus. 


\section{Sumário}

Lista de abreviaturas, símbolos e siglas

Lista de tabelas

Lista de figuras

Resumo

Summary

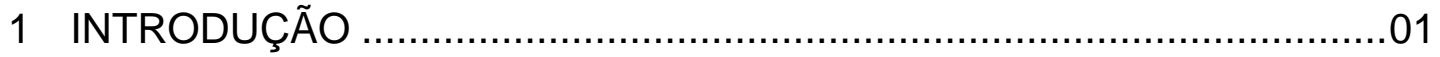

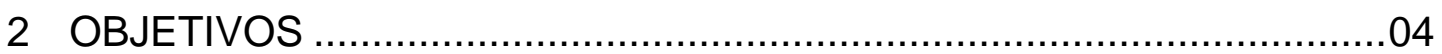

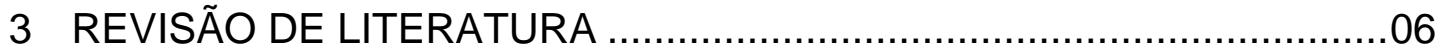

3.1 Teste Sensitivo Quantitativo (TSQ) ..................................... 07

3.2 Neuralgia Pós-herpética Trigeminal ...................................12

3.3 Neuralgia Idiopática do Trigêmeo ..........................................16

3.4 Síndrome da Ardência Bucal .................................................19

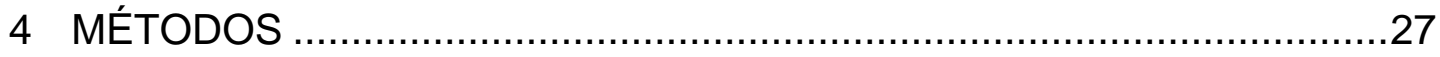

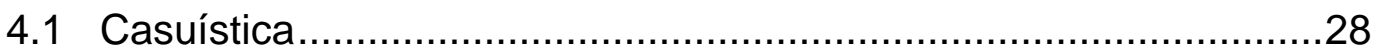

4.1.1 Critérios de exclusão ................................................28

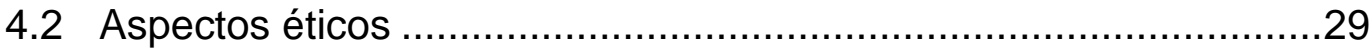

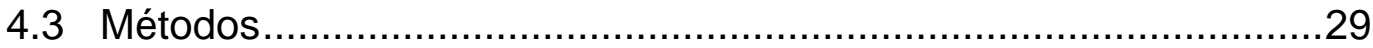

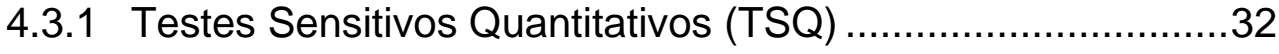

4.3.1.1 Detecção de dor - limiares álgicos de superfície .....32

4.3.1.2 Detecção mecânica - percepção tátil superficial .....33 
4.3.1.3 Detecção térmica - percepção das temperaturas (quente e frio)

4.3.2 Avaliação gustativa ...............................................35

4.3.3 Avaliação olfativa ............................................... 36

4.3.4 Avaliação salivar quantitativa.................................... 37

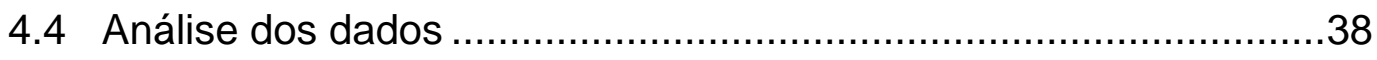

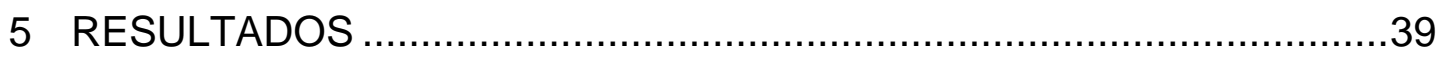

5.1 Características gerais da amostra ......................................40

5.2 Testes sensitivos quantitativos ......................................... 41

5.2.1 Limiares dolorosos de superfície ...............................41

5.2.2 Detecção mecânica (percepção tátil superficial) e detecção de temperaturas (frio e calor) ...........................44

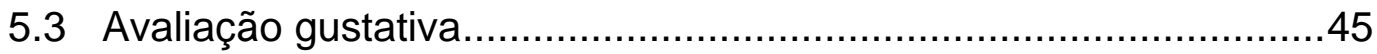

5.4 Avaliação olfativa..............................................................46

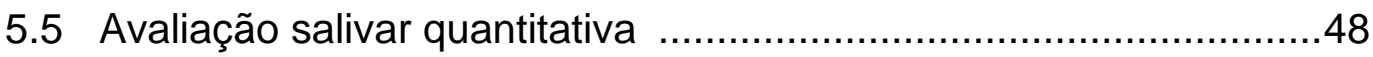

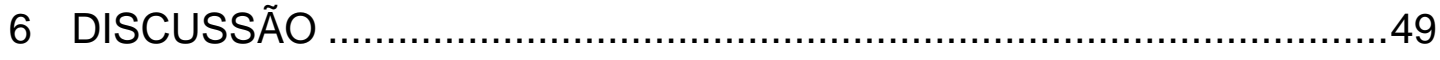

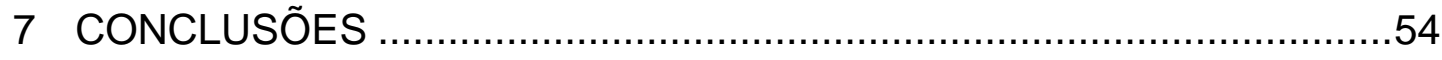

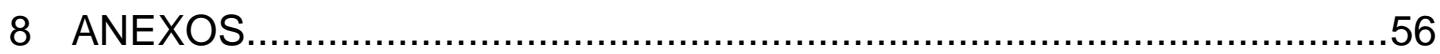

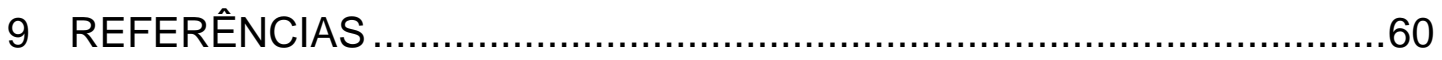

Apêndices 


\section{Lista de Abreviaturas, Símbolos e Siglas}

\begin{tabular}{|c|c|}
\hline$\circledR$ & - Marca registrada \\
\hline${ }^{\circ} \mathbf{C}$ & - Grau Celsius \\
\hline CAPPesq & $\begin{array}{l}\text { - Comissão de Ética para Análise de Projetos de } \\
\text { Pesquisa do HCFMUSP }\end{array}$ \\
\hline $\mathrm{dm}^{3}$ & - Decímetro cúbico \\
\hline Dp & - Desvio-padrão \\
\hline EDOF & - Equipe de Dor Orofacial \\
\hline EVA & - Escala Visual Analógica \\
\hline EUA & - Estados Unidos da América \\
\hline FAPESP & $\begin{array}{l}\text { - Fundação de Amparo à Pesquisa do Estado de São } \\
\text { Paulo }\end{array}$ \\
\hline g & - Grama \\
\hline HC-FMUSP & $\begin{array}{l}\text { - Hospital das Clínicas da Faculdade de Medicina da } \\
\text { Universidade de São Paulo }\end{array}$ \\
\hline $\mathrm{HZ}$ & - Herpes zoster \\
\hline IASP & - International Association for the Study of Pain \\
\hline Min & - Minuto \\
\hline mL & - Mililitro \\
\hline mm & - Milímetro \\
\hline $\mathrm{mm}^{2}$ & - Milímetro quadrado \\
\hline mol & - Molar \\
\hline NIT & - Neuralgia idiopática do trigêmeo \\
\hline NPH & - Neuralgia pós-herpética trigeminal \\
\hline
\end{tabular}


s

SAB

SNC

SNP

TNF

TSQ

VVZ

V1

V2

V3

- Segundo

- Síndrome da ardência bucal

- Sistema nervoso central

- Sistema nervoso periférico

- Fator de necrose tumoral

- Testes sensitivos quantitativos

- Vírus varicela zoster

- Ramo oftálmico do nervo trigêmeo

- Ramo maxilar do nervo trigêmeo

- Ramo mandibular do nervo trigêmeo 


\section{Lista de Tabelas}

Tabela 1 - Características demográficas dos grupos de estudo e controle: os controles foram divididos em dois grupos de acordo com a faixa etária $(\mathrm{N}=120)$ .40

Tabela 2 - Comparação dos limiares álgicos de superfície entre os ramos trigeminais, nos grupos de estudo $(\mathrm{N}=60)$

Tabela 3 - Comparação dos limiares álgicos de superfície entre os grupos de estudo e controles ( $N=120)$

Tabela 4 - Comparação dos limiares álgicos de superfície entre os grupos de estudo e controles na região intra-oral $(N=120)$.....43

Tabela 5 - Comparação dos valores dos testes térmicos e mecânicos, em todos os ramos do trigêmeo, entre os ramos trigeminais e entre os grupos $(\mathrm{N}=120)$

Tabela 6 - Comparação dos limiares olfativos entre os grupos de estudo e controles $(\mathrm{N}=120)$

Tabela 7 - Comparação do fluxo salivar quantitativo entre os grupos de estudo e controles (MI/Min) ( $\mathrm{N}=120)$ 


\section{Lista de Figuras}

Figura 1 - Pontos de aplicação dos testes sensitivos nos ramos trigeminais

Figura 2 - $\quad$ Algiômetro de superfície - Micromar® 32

Figura 3 - Estesiômetro manual (microfilamentos de Von Frey) 33

Figura 4 - Termoalgiômetro Thermosensi TS2 34

Figura 5 - Frascos das soluções aplicadas nos testes gustativos .35

Figura 6 - Frascos das soluções de isopropanol e substâncias aplicadas nos testes olfativos .36

Figura 7 - Avaliação quantitativa de fluxo salivar e Balança Acculab $\AA$

Figura 8 - Comparação dos limiares álgicos de superfície entre os grupos de estudo e controles $(n=120)$

Figura 9 - Comparação dos limiares gustativos (doce, salgado, amargo e azedo) entre os grupos de estudo e controles (concentrações molares) $(n=120)$

Figura 10 - Comparação entre os grupos de estudo e controles com relação ao teste olfativo de identificação de substância $(n=120)$ 


\section{Resumo}

Siviero M. Avaliação sensitiva, gustativa, olfativa e salivar em doentes com neuralgias trigeminais. [dissertação]. São Paulo: "Faculdade de Medicina, Universidade de São Paulo"; 2011.

Neuralgia pós-herpética trigeminal (NPH), neuralgia idiopática do trigêmeo (NIT) e síndrome da ardência bucal (SAB) são doenças neuropáticas da face, caracterizadas por dor na ausência de sinais que evidenciem a causas. Este estudo teve por objetivos determinar as características sensitivas, olfativas, gustativas e salivares em doentes com NPH, NIT e SAB comparados a controles. Foram avaliados 20 doentes de cada grupo, diagnosticados de acordo com critérios da International Association for the Study of Pain (IASP), e 60 indivíduos saudáveis, através de um protocolo sistematizado que incluiu os seguintes testes quantitativos sensitivos: limiares térmicos (frio e calor), limiares mecânicos tácteis, limiares dolorosos de superfície, limiares gustativos (doce, azedo, salgado e amargo), limiares olfativos e fluxo salivar. Os testes foram realizados no território de inervação trigeminal. Os dados foram analisados através dos testes estatísticos ANOVA 1 fator, Tukey, Kruskal-Wallis e Dunn, e o nível de significância foi de $5 \%$. Os limiares térmicos de frio foram diferentes (maiores) somente no ramo mandibular dos doentes com NPH $(p=0,001)$ e os limiares térmicos de calor foram diferentes (maiores) em todos os ramos trigeminais nos doentes com NPH e SAB ( $p=0,001)$; a sensibilidade mecânica táctil estava alterada no ramo mandibular de doentes com NPH $(p=0,001)$ e em todos os ramos trigeminais dos doentes com SAB ( $p=0,001 ; p=0,004$ e $p=0,001)$; os limiares gustativos salgado e doce, além do limiar olfativo, foram maiores em todos os doentes quando comparados aos controles $(p=0,004 ; p=0,001$ e $\mathrm{p}=0,0389$ ); o sabor ácido obteve os menores limiares e não foram encontradas diferenças para a identificação do sabor amargo ou na avaliação salivar quantitativa $(p=0,1694$ e $p=0,001)$. Este estudo apresentou evidências de anormalidades sensitivas nos doentes com dor neuropática trigeminal, tanto somestésicas como gustativas e olfativas. A sensibilidade somatosensitiva apresentou-se mais alterada nos doentes com NPH e SAB quando comparados a NIT e aos controles. Mecanismos periféricos e centrais relacionados à percepção e modulação sensitiva podem estar envolvidos na fisiopatologia dos achados aqui observados.

Descritores: Neuralgia facial; Modalidades sensoriais; Limiar sensorial; Neuralgia do trigêmeo; Neuralgia pós-herpética; Síndrome da ardência bucal; Dor orofacial. 


\section{Summary}

Siviero M. Somesthetic, gustatory, olfactory function and salivary flow in patients with neuropathic trigeminal pain. [dissertation]. São Paulo: "Faculdade de Medicina, Universidade de São Paulo"; 2011.

Trigeminal postherpetic neuralgia (PHN), idiopathic trigeminal neuralgia (ITN) and burning mouth syndrome (BMS) are painful neuropathies with no clear signs about their causes. The objectives of this study were to determine somatosensory, olfactory, gustative and salivary characteristics of patients with PHN, ITN and BMS compared to controls. Twenty patients from each group, diagnosed according to the criteria from the International Association for the Study of Pain (IASP), and 60 healthy controls were evaluated with a systematized quantitative approach which included thermal (cold and warm), mechanical (tactile), pain, gustative (sweet, sour, salty and bitter) and olfactory thresholds, and quantitative salivary flow evaluation. Data were analyzed with ANOVA 1 factor, Tukey, Kruskal-Wallis and Dunn tests with a level of significance of $5 \%$. Thermal thresholds for cold were different (higher) only in the mandibular branch of patients with $\operatorname{PHN}(\mathrm{p}=0.001)$ and warm thresholds were higher in all trigeminal branches of PHN and BMS $(p=0,001)$; tactile mechanical sensitivity was altered at the mandibular branch of PHN $(p=0,001)$ and in all trigeminal branches of BMS $(p=0,001 ; p=0,004$ e $p=0,001)$. The salty, sweet and olfactory thresholds were higher in all studied groups $(p=0,004 ; p=0,001$ e $p=0,0389)$; the sour threshold was lower and there were no differences in bitter taste or salivary flow $(p=0,1694$ e $p=0,001)$. This study showed evidences of somatosensory, gustative and olfactory abnormalities in patients with neuropathic orofacial pain. Somatosensory findings were discrete in ITN and more common in PHN and BMS. Peripheral and central mechanisms of perception and modulation could be involved in the physiopathology of these findings.

Descriptors: Facial neuralgia; Modalities, sensorial; Sensory thresholds; Trigeminal neuralgia; Neuralgia, postherpetic; Burning mouth syndrome; Facial pain. 
1 INTRODUÇÃO 


\section{INTRODUÇÃO}

Dentre as síndromes dolorosas, a neuralgia pós-herpética trigeminal (NPH), a neuralgia idiopática do trigêmeo (NIT) e a síndrome da ardência bucal (SAB) apresentam destaque pelo caráter neuropático e pela localização facial, sendo mais prevalentes na terceira idade. A NIT e a SAB apresentam ainda fisiopatologia e etiologia desconhecidas, o que faz com que estudos sejam necessários para elucidar os seus mecanismos e auxiliar no tratamento desses doentes.

A dor de origem neuropática é atribuída à desmielinização, degeneração valeriana e/ou esclerose do sistema nervoso periférico (SNP) e/ou central (SNC) e inclui alterações como atrofia e morte celular e fenômenos neuroplásticos, que representam clinicamente manifestações sensitivas atípicas. Nas dores faciais, além das anormalidades somestésicas, alterações nas percepções gustativa e olfativa podem estar presentes, evidenciando mecanismos centrais na fisiopatologia dolorosa. Apesar dos avanços na compreensão da dor neuropática, ainda há carência de estudos nas síndromes neuropáticas trigeminais, a despeito da sua alta prevalência na população idosa.

A avaliação sensitiva permite o reconhecimento de anormalidades que podem ser bastante úteis, contribuindo para a identificação do comprometimento nervoso e para a compreensão fisiopatológica dessas doenças. Do mesmo modo, existem poucos estudos que avaliem o fluxo 
salivar nessas síndromes apesar de ser bastante conhecida a importância da saliva na transdução de informações sensitivas orais. 
2 OBJETIVOS 


\section{OBJETIVOS}

Este estudo teve por objetivos avaliar doentes com Neuralgia PósHerpética (NPH), Neuralgia Idiopática do Trigêmeo (NIT) e Síndrome da Ardência Bucal (SAB), em comparação a indivíduos saudáveis, quanto às características quantitativas de:

1. Limiares sensitivos somestésicos orofaciais;

2. Limiares gustativos e olfativos; e

3. Fluxo salivar. 


\section{REVISÃO DE LITERATURA}




\section{REVISÃO DA LITERATURA}

\subsection{Testes Sensitivos Quantitativos (TSQ)}

A sensibilidade é essencial para o aprendizado das informações do ambiente em que vivemos. No século XVII, John Locke propôs a teoria da Tabula Rasa que postulava haver ausência de qualquer conhecimento prévio ao nascimento armazenado no indivíduo. Sendo assim, todo o aprendizado dependeria essencialmente das experiências sensitivas vivenciadas. Atualmente, esse conceito não é mais considerado verdadeiro, mas sabe-se que as experiências continuam importantes no desenvolvimento.

O conjunto de todas as percepções conscientes que temos oriundos da pele, vísceras, músculos e articulações, denomina-se somestesia (Gardner; Martin, 2003). Nas modalidades somestésicas incluem-se o tato, vibração, textura, estereognosia (que depende de integração de sistemas sensitivos), a sensibilidade térmica (frio e calor) e a sensibilidade dolorosa, ou nocicepção. A dor é definida como uma experiência sensitiva e/ou emocional desagradável associada a um dano tecidual real ou em potencial (Merskey; Bogduk, 1994). As sensibilidades especiais incluem a gustação, a olfação, a visão e a audição. Todas essas sensações são recebidas através dos nossos sentidos na forma de energia classificada nas diferentes modalidades (somestésicas, visão, audição, gustação e olfação) que as 
traduzem para a linguagem neural através da transdução. Os estímulos provenientes do ambiente podem ou não ser transformados em percepção, excluindo-se aqueles que não atingem a consciência servindo apenas ao controle motor e às funções orgânicas (Lent, 2003).

Assim sendo, a sensibilidade pode ser definida como a capacidade que o SN tem de identificar um estímulo, em nível consciente ou inconsciente, advindo de qualquer modalidade. Os sistemas sensitivos são então encarregados de recolher informações do meio que nos rodeia e do interior do organismo através de células especializadas que transmitem as informações ao SNC para seu processamento e análise. Todo sistema sensitivo é composto de neurônios interligados formando circuitos neurais que processam a informação que chega do ambiente. O ambiente, seja ele externo ou interno, é, portanto, a origem dos estímulos sensitivos. Eles geralmente incidem sobre uma superfície onde se localizam as células denominadas receptores sensitivos, sendo estes os responsáveis pela transdução. Os receptores também são chamados de células primárias ou de primeira ordem. Essas células podem ou não ser neurônios, e se conectam através de sinapses com neurônios secundários ou de segunda ordem, e estes com neurônios terciários ou de terceira ordem (Lent, 2003). Essa informação codificada é utilizada pelo indivíduo nas operações perceptuais ou de controle funcional necessárias em cada momento. A transdução consiste na transformação da energia do estímulo ambiental em potenciais bioelétricos gerados pelas membranas dos receptores. A seguir, o potencial receptor pode provocar a gênese de potenciais de ação na mesma 
célula, ou de outros potenciais no neurônio de segunda ordem mediante transmissão sináptica e, assim sucessivamente aos neurônios de ordem superior. Ao longo dessa cadeia de transmissão, entram em ação diferentes mecanismos de integração sináptica que possibilitam a análise de diversos atributos dos estímulos e depois a sua utilização em outros processos fisiológicos ou na reconstrução mental de objetos, característica da percepção (Lent, 2003). A interação sensitiva é essencial no processo de percepção do ambiente, e assim os sistemas sensitivos não funcionam de maneira isolada.

Há quatro características sensitivas que são: modalidade, localização, intensidade e duração. A modalidade foi proposta em Müller em 1826 e é a classe do estímulo (ex: paladar e seus subtipos: doce, azedo, salgado, amargo; tato e seus subtipos: discriminativo, pressão, rigidez, textura), determinada geralmente por um receptor específico; a localização é a habilidade do receptor em reconhecer a parte do corpo onde ocorreu o estímulo; a intensidade e duração estão relacionadas à amplitude do estímulo e ao tempo de aplicação (Gardner; Martin, 2003). A distribuição dos receptores ativados fornece informações importantes e específicas sobre a localização espacial, tamanho e forma, e resolução de detalhes; essas habilidades estão ligadas ao campo receptor, ou seja, que determina a localização topográfica específica da informação sensitiva (Corey; Roper, 1992). A densidade de receptores em cada região do corpo determina a quantidade de detalhes; quanto maior a densidade, como no caso das mãos e da boca, maior essa definição. Já os receptores de olfato e paladar estão 
distribuídos de acordo com o espectro de energia da modalidade, e no caso da audição, de acordo com a frequência. A percepção de diferentes intensidades é importante para diferenciar dois estímulos em que a magnitude é a diferença entre eles (Gardner; Martin, 2003).

A menor força de um estímulo que o indivíduo é capaz de perceber é chamada de limiar sensitivo. Os limiares podem ser alterados devido a problemas no receptor, nos aferentes primários ou no processamento central. Também podem ser modulados por aspectos emocionais ou ambientais. Identificar um estímulo depende da percepção propriamente dita e do julgamento do indivíduo de ter realmente percebido este estímulo (Gardner; Martin, 2003). A integração sensitiva se dá nos centros de processamento, sendo que existem interneurônios inibitórios nos sistemas superiores que colaboram nesse processo (Sherrington, 1947).

As informações sensitivas dos nervos cranianos penetram no sistema nervoso central e distribuem-se basicamente em três regiões: nos núcleos trigeminais (informações somestésicas da face), no núcleo solitário (informações gustativas) e no núcleo coclear (informações auditivas). As informações visuais e olfativas seguem através de outras vias que não as do tronco encefálico. Também nesta região encontra-se a formação reticular, que parece controlar a informação aferente sensitiva que deve atingir ou não níveis mais altos do sistema nervoso central, como é o caso da percepção do contato das roupas ao corpo, participando do sistema supressor descendente de dor (Melzack; Wall, 1965; Crossman; Neary, 2002). 
A necessidade de avaliação das diferentes modalidades sensitivas levou ao desenvolvimento de métodos que investigam os limiares e fenômenos como somação temporal e alodínia, tendo sido denominados testes sensitivos quantitativos (TSQ). Os achados permitem a evidenciação de sinais relacionados à hiperalgesia primária e/ou secundária, e de sensibilização central. Perda sensitiva também pode ser investigada, além da localização e extensão das anormalidades observadas. Os doentes com dor crônica apresentam frequentemente anormalidades sensitivas que podem ser determinadas por esses testes (Felix; Widerström-Noga, 2009), porém poucos estudos investigaram as dores orofaciais (Forssell et al., 2007; Juhl et al., 2008). Dentre as modalidades avaliadas, estudam-se frequentemente anormalidades somestésicas; porém, quando a dor é na face, outras sensibilidades tais como a gustação e a olfação também podem estar alteradas (Grushka; Sessle, 1991; Granot; Nagler, 2005; Siqueira et al., 2006b). Os TSQ apresentam-se particularmente indicados quando se suspeita de envolvimento neuropático na dor, porém dependem da participação do doente por se tratarem de testes psicofísicos, e sendo assim alguns grupos etários, como crianças, ou morbidades como doenças psiquiátricas e lou neurológicas, podem impedir a sua realização. De qualquer maneira, a avaliação clínica é essencial no diagnóstico e os TSQ devem ser utilizados como exames complementares, além do seu papel importante como auxiliares na elucidação de mecanismos fisiopatológicos em pesquisa (Felix; Widerström-Noga, 2009). 
O desenvolvimento desses testes iniciou-se em 1905, quando Von Frey criou um método em que se utilizavam pêlos de cavalo presos a uma haste para a avaliação da sensibilidade cutânea. Entretanto, este método era bastante impreciso, e seu conhecimento tem atualmente importância histórica (Levin et al., 1978). Nas últimas décadas, diversos sistemas eletrônicos foram desenvolvidos de forma que a avaliação das sensibilidades passou a ser mais completa e precisa (Price, 1994). As acuidades visual, auditiva, olfativa e gustativa também podem ser avaliadas quanto às suas magnitudes através de testes, e recentemente iniciaram-se os estudos dessas sensibilidades em doentes com dor orofacial (Siqueira et al., 2006b). É importante observar que, nas percepções orais, a saliva apresenta um papel importante na concentração ou diluição de substâncias para que ocorra a transdução sensitiva, tanto gustativa quanto somestésica trigeminal (Buck, 2003). Diversos métodos podem ser utilizados para a sua avaliação quantitativa (Pupo et al., 2002).

\subsection{Neuralgia pós-herpética trigeminal (NPH)}

A NPH caracteriza-se como uma complicação em indivíduos que foram primariamente infectados pelo vírus da varicela zoster (VVZ), que é adquirido de forma respiratória, comumente ainda na infância, sendo sua manifestação inicial conhecida como varicela ou catapora (Kost; Straus, 1996; Nurmikko; Bowsher, 1990). A disseminação desse vírus provoca 
manchas, bolhas e vesículas espalhadas por toda a pele e mucosas, inclusive áreas intra-orais (Tidwell et al., 1999). Cefaléia, naso-faringite, anorexia e febre podem ocorrer como parte do quadro clínico (Siqueira e Teixeira, 2001). Sabe-se que $0,5 \%$ dos indivíduos infectados primariamente pelo VVZ não apresentam sintomas dolorosos; nos demais, a dor normalmente manifesta-se horas ou dias antes do início do aparecimento das lesões herpéticas (Teixeira; Okada, 1999).

Após a resolução da infecção, o VVZ se aloca nos gânglios sensitivos do sistema nervoso, onde pode permanecer latente por décadas devido à atividade imunológica supressora à sua ativação (Thyregod et al., 2007). Na presença de comprometimento imunológico decorrente de estado geral, pode haver reativação do vírus, porém nessa segunda manifestação a infecção se localiza em um dermatômero do corpo correspondente à inervação sensitiva do gânglio afetado, sendo então conhecida como herpes zoster (HZ) (Teixeira; Okada, 1999). Estima-se que, na população adulta, $25 \%$ dos indivíduos acometidos anteriormente pela catapora possam desenvolvê-la (Haanpäa et al., 2000).

O indivíduo afetado pelo $\mathrm{HZ}$ apresenta um quadro clínico de erupções vesiculares, localizadas em um território de inervação sensitiva unilateral (Dworkin; Portenoy, 1996). A dor nessa fase é classificada como aguda e costuma regredir em semanas ou meses após a erupção das vesículas (Teixeira; Okada, 2001). Quando a dor persiste e se torna crônica, o que pode ocorrer em cerca de $15 \%$ a $40 \%$ dos casos de $\mathrm{HZ}$, caracteriza-se então 
o quadro de NPH. Esta, quando afeta o nervo trigêmeo, é denominada NPH trigeminal (Petersen; Rowbotham, 2010).

Idade e gravidade de $\mathrm{HZ}$ são fatores preditores da evolução para a NPH (Petersen et al., 2010). Quando esta se desenvolve, o doente apresenta dor crônica e intensa sensação de ardência na área acometida, sendo mais prevalente em indivíduos acima dos 70 anos de idade e em mulheres (Petersen; Rowbotham, 2010). Ainda há controvérsias com relação à duração da dor e o diagnóstico de NPH. Entretanto, mais de três meses de dor após o desaparecimento das erupções cutâneas é o período de tempo mais aceito para que um indivíduo seja diagnosticado com NPH.

A NPH acomete em $15 \%$ a $20 \%$ dos casos o nervo trigeminal, sendo o ramo oftálmico (V1) o mais afetado. Quando ocorre nos ramos maxilar (V2) e mandibular (V3), geralmente é intra-oral (Brown, 1976). A região trigeminal é a segunda mais afetada, ocupando o tórax a primeira colocação (55\%) (Teixeira; Okada, 1999). Outros nervos sensitivos cranianos também podem ser acometidos, porém o trigêmeo é responsável por $94 \%$ dos casos, sendo que o V1 corresponde a $73,1 \%$ dos doentes, seguido do V2 $(8,8 \%)$ e do V3 (5,9\%) (Alvarez e al., 2007). Associações de ramos trigeminais também podem ser observadas (Nurmikko; Bowsher, 1990). Raramente ocorre ao mesmo tempo o acometimento de diferentes troncos nervosos (Teixeira; Okada, 1999).

A fisiopatologia da NPH ainda é pouco conhecida. Foram observadas evidências em necropsias realizadas no gânglio sensitivo de doentes com $\mathrm{NPH}$ de que a cronicidade da dor estaria associada à perda das fibras 
nervosas de grosso calibre e à relativa preservação das fibras finas (Noordenbos, 1959; Watson et al., 1988; Watson et al., 1991). Porém, essas evidências são controversas, uma vez que em outro estudo foi observada degeneração nervosa de ambos os calibres das fibras de forma similar (Zacks et al., 1964). Na avaliação periférica neural, em tecidos provenientes de biópsias de pele da área afetada, também foi observada degeneração nervosa ( $40 \%$ de perda funcional) que se correlacionou com a evolução do HZ para a NPH de maneira positiva (Petersen et al., 2010).

A dor crônica característica da NPH pode ser acompanhada por parestesia, hiperestesia, alodínia e alterações sensitivas. Alguns estudos relatam perda de sensibilidade em diferentes modalidades nestes pacientes. Alvarez et al. (2007) estudaram a sensibilidade facial em 18 pacientes com diagnóstico de NPH, comparando o lado acometido pela doença com o lado oposto. Os autores observaram que, em $73,7 \%$ da amostra, o descritor mais comumente utilizado para a dor foi ardência e/ ou queimação. A média de duração da dor foi de 52,9 meses. Sendo o mais afetado pela NPH, o V1 apresentou marcantemente mais alterações somatosensitivas do que os outros ramos, incluindo anormalidades térmicas ao frio, a estímulos mecânicos e a estímulos dolorosos de superfície. Porém, também foram encontradas anormalidades em V2 e V3, independentemente de terem sido afetados pelo vírus.

Petersen e Rowbotham analisaram, em 2010, a história natural da função sensitiva após o $\mathrm{HZ}$, tendo acompanhado 94 doentes com elevado risco para o desenvolvimento de $\mathrm{NPH}$ durante um período de seis meses, 
sendo estes indivíduos imunocompetentes e saudáveis, com mais de 50 anos de idade e com uma média diária de dor nas últimas 48 horas anteriores de 2 através da escala visual analógica (EVA). Na última avaliação, $32 \%$ da amostra ainda permaneciam com queixas de dor e preenchiam os critérios para o diagnóstico do NPH. Suas características iniciais foram médias de dor mais intensas ao longo das avaliações, maiores índices de dormência e dor profunda, de disestesia, percepção sensitiva alterada, áreas de anormalidades sensitivas mais dispersas e maior gravidade de alodínia. Os testes de sensibilidade térmica e mecânica foram os que apresentaram maiores alterações. Os resultados deste estudo mostraram que intervir precocemente nas queixas do doente pode prevenir a evolução da HZ para a NPH. Dados semelhantes foram observados posteriormente, reforçando o aspecto de que a alta intensidade da dor nas primeiras 48 horas após $\mathrm{o} \mathrm{HZ}$ pode predizer o desenvolvimento da NPH (Thyregod et al., 2007).

\subsection{Neuralgia idiopática do trigêmeo (NIT)}

A NIT é descrita como uma síndrome dolorosa facial neuropática, sendo a forma mais comum de dor na face em pessoas na terceira idade. Diversos estudos epidemiológicos têm demonstrado que a incidência anual é de cerca de 4 a 5 casos a cada 100.000 indivíduos (Katusic et al., 1990). A faixa etária mais afetada é entre os 50 a 70 anos de idade, e, apenas $10 \%$ 
dos casos apresentam seus primeiros sintomas antes dos 40 anos de idade. A NIT acomete mais mulheres do que homens em uma proporção de 5:1 (Prasad; Galetta, 2009).

Muitas teorias foram propostas para explicar a fisiopatologia da NT, mas, até o momento, nenhuma delas explica todos os aspectos clínicos e achados radiológicos desta condição. Em boa parte dos casos observa-se a compressão da raiz trigeminal próxima à zona de entrada da raiz trigeminal no SNC por vasos sanguíneos, principalmente artérias, mas ocasionalmente por veias. A pressão ocasionada promoveria a desmielinização das fibras sensitivas trigeminais com consequente despolarização anormal e a geração de impulsos ectópicos (Van Kleef et al., 2009). Apesar de esses achados serem encontrados em cerca de $70 \%$ dos indivíduos com NIT, esse mecanismo não é suficiente para explicar o aparecimento da doença em indivíduos que não apresentam essa compressão. Tumores como meningiomas ou schwannomas entre outros são encontrados em $5 \%$ dos casos, o que torna imprescindíveis exames de imagem (Teixeira, 1984). Evidências recentes apontaram para o possível envolvimento de canais de sódio voltagem dependentes na fisiopatologia da NIT, principalmente os subtipos Nav1.3 e Nav1.7, o que mostra que a NIT pode ser uma canalopatia (Siqueira et al., 2009).

A NIT é caracterizada como uma dor localizada unilateral, geralmente paroxística, lancinante e descrita como choque elétrico, cuja distribuição respeita o território de inervação de um ou mais ramos trigeminais (Teixeira, 1984). Eventualmente a dor irradia-se para fora da área de distribuição do 
nervo trigêmeo. A dor pode apresentar-se de forma espontânea ou ser desencadeada por estímulos não nocivos cutâneos e/ou orais, tais como pentear os cabelos, escovar os dentes, mastigar, fazer a barba ou enxugar o rosto, devido ao contato com áreas específicas denominadas de "zona gatilho" (Devor et al., 2002). Eventualmente, a dor pode desencadear fenômenos neurovegetativos como salivação, lacrimejamento, ruborização da face e rinorréia (Penman, 1950).

Diante da dor, muitos doentes acabam por anular por completo suas tarefas do dia a dia, impossibilitados de exercerem cuidados básicos de higiene ou de convívio social, o que compromete intensamente sua qualidade de vida e os torna deprimidos e isolados (Koopman et al., 2009; Siqueira et al., 2010). A dor é intermitente, com períodos refratários, sendo necessários alguns minutos para que seja novamente desencadeada. Alguns doentes apresentam períodos de remissão, principalmente no início da doença, que podem durar dias, semanas e/ou meses. Estes períodos de remissão podem ser muito longos, mas crises muito frequentes podem ser descritas como contínuas (Teixeira, 1998). Ao longo do curso da doença, esses períodos de remissão vão se tornando cada vez mais curtos, chegando até mesmo a desaparecer (Teixeira, 1998; Siqueira; Teixeira, 2001). A dor normalmente não acorda o doente durante o sono, sendo a NIT de caráter diurno com exacerbação no período matinal. Entre as crises, os doentes podem apresentar sensação de hipoestesia sem outros sintomas concorrentes (Bayer; Stenger, 1979; Devor et al., 2002). Normalmente, observa-se que as crises geralmente ocorrem durante meses frios ou 
aqueles quentes e úmidos, ou seja, com baixas condições barométricas (Teixeira, 1984).

Os ramos trigeminais mais afetados são o V2 e o V3, isoladamente ou associados, sendo a dor mais rara em V1, em oposição à NPH (5\% dos casos) (Siqueira et al., 2009a).

Alguns estudos recentes têm mostrado que anormalidades sensitivas podem ser encontradas nos territórios de inervação trigeminal em doentes com NIT (Jääskeläinen et al., 2005; Sinay et al., 2003; Siqueira et al., 2006a). Ao exame clínico, cerca de $15 \%$ a $25 \%$ desses doentes podem apresentar tais alterações. Em geral as anormalidades são discretas e podem ser observadas além dos ramos trigeminais afetados pela dor, ou seja, em áreas adjacentes e até no lado oposto (Sinay et al., 2003). As

anormalidades térmicas e dolorosas são as mais frequentes (Sinay et al., 2003). O reflexo córneo-palpebral apresenta-se comprometido em $20 \%$ dos doentes, e queixas de dormência são até mais prevalentes do que anormalidades sensitivas evidenciáveis por TSQ (Siqueira, 2006c).

\subsection{Síndrome da ardência bucal (SAB)}

O ardor bucal é uma queixa de ordem multifatorial que envolve fatores sistêmicos e psicológicos (Formaker; Frank, 2000). Esta condição clínica apresenta-se como uma sensação dolorosa caracterizada por ardência e/ou queimação, localizada na mucosa oral em diversos sítios anatômicos, e deve 
ser diferenciada da SAB. O ardor bucal apresenta uma causa evidenciável e, portanto, a SAB é um diagnóstico idiopático e de exclusão (Grushka, 1987). Esses sintomas podem vir acompanhados de secura bucal e de anormalidades de paladar (Netto et al., 2011). Na avaliação, devem ser identificadas alterações locais e/ ou sistêmicas que poderiam estar associadas à sintomatologia observada através de exames clínicos e laboratoriais (López-Jornet et al., 2010).

Dentre as condições que devem ser excluídas para o diagnóstico da SAB, estão: xerostomia, irritação por próteses dentárias, candidíase oral, outras infecções e lesões orais, respiração bucal, deficiências vitamínicas, minerais e hormonais, doenças gástricas, reumatológicas entre outras (Nasri et al., 2007). As estratégias de tratamento dependem do diagnóstico acurado. Após sua confirmação, medicações de uso corrente na dor neuropática devem ser utilizadas (Grushka; Sessle, 1991, Nasri et al., 2000).

O sítio anatômico mais frequentemente afetado é a língua, seguido por lábios, mucosa jugal, gengiva e palato. Entretanto, é frequente que mais de uma área esteja afetada (Nasri et al., 2002; Netto et al., 2011). De acordo com a Associação Internacional para o Estudo da Dor (International Association for the Study of Pain - IASP), a queixa do doente deve ter uma duração contínua de ao menos quatro a seis meses para ser classificada como SAB (Merskey; Bogduk, 1994). Essa queixa pode persistir por meses ou até mesmo anos após o diagnóstico. A literatura relata um período médio de 3,5 anos de duração nos doentes avaliados (Van der Waal, 2001). O início da dor geralmente é espontâneo (Forssell et al., 2002); entretanto, 
alguns doentes relacionam este a algum evento anterior, tal como procedimentos odontológicos e doenças locais ou sistêmicas prévias (Grushka, 1987).

Os dados referentes à prevalência desta doença são extremamente variáveis. Acredita-se que o amplo número de metodologias utilizadas, somado à inexistência, em alguns desses estudos, de exames clínicos e/ou laboratoriais que a diferenciem do ardor bucal e colaborem com sua identificação, sejam responsáveis por este achado (López-Jornet et al., 2010). A literatura relata uma prevalência de $0,7 \%$ a $18 \%$ da população adulta (Hakeberg et al., 1997), sendo que os indivíduos mais afetados apresentam idade entre 45 e 60 anos. A SAB afeta mais comumente as mulheres, quando comparadas aos homens, em proporções que vão desde 3:1 até 16:1 (Lamey, 1996; Nasri et al., 2002).

Sua etiologia é idiopática, e as evidências atuais classificam-na como uma doença neuropática. A teoria aceita atualmente é a de que ocorra desinibição trigeminal a partir da perda parcial ou total da função do nervo corda do tímpano, ramo do nervo facial, responsável pela aferência gustativa. A interação entre os dois sistemas (paladar e dor) é regulada por interneurônios do SNC (Bartshuk et al., 1989, Bergdahl; Bergdahl, 1999). Ainda assim, diversos autores acreditam que se trata de uma doença multifatorial com influência de diversos aspectos tais como a menopausa, alterações hormonais, problemas psicológicos, deficiências nutricionais, alterações salivares (hipossalivação ou xerostomia), entre outras. Devido a essa variabilidade, é possível que a SAB possa ser subdividida em grupos 
de acordo com o envolvimento de aspectos locais, sistêmicos e psicológicos (Lamey et al., 2005). Dentre as alterações locais destacam-se os hábitos parafuncionais, infecções por fungos e bactérias, alergias, alterações neuronais e/ou vasculares e disfunções de glândulas salivares (Bergdahl; Anneroth, 1993). Os transtornos hormonais, doenças crônicas, deficiências nutricionais e os efeitos de alguns medicamentos são algumas das alterações sistêmicas que podem estar relacionadas à SAB. Além disso, algumas alterações psicológicas têm sido associadas à doença, como depressão, ansiedade, hipocondria, cancerofobia e somatização (LópezJornet et al., 2010).

Consequentemente, por estes e outros fatores, a SAB é considerada na literatura médica e odontológica como uma doença de difícil diagnóstico. Os doentes costumam ter queixas frequentes de dor e alterações de paladar. Assim, é cada vez mais comum na literatura pesquisas que relacionem esses sintomas (Femiano et al., 2008).

A teoria mais aceita é a de que a SAB seja caracterizada por dor oral fantasma, até recentemente considerada como induzida por um dano no sistema gustativo (Bartoshuk et al., 2005). Com o estímulo das terminações nervosas gustativas, são enviados ao cérebro tanto estímulos excitatórios quando inibitórios, intermediados nos dois terços anteriores da língua pelo nervo corda do tímpano, que é um ramo do nervo facial, e pelo nervo glossofaríngeo na porção mais posterior. O nervo corda do tímpano atuaria inibindo também a resposta gustativa da região posterior da língua (Miller, 1976). Anormalidades relacionadas ao nervo corda do tímpano poderiam 
permitir uma desinibição dos nervos trigêmeo e glossofaríngeo, intensificando sensações somatosensitivas como a dor, sensação táctil e de secura bucal (Bartoshuk, 1988). Porém, evidências mais recentes indicam que o dano primário é provavelmente no sistema trigeminal, e que o achado gustativo seja secundário a este. Estudos neurofisiológicos sugerem que o SNP e o SNC estariam envolvidos na patogenia da doença. De qualquer modo, a presença de alterações gustativas e o fato de alguns doentes com SAB apresentarem hipersensibilidade ao reconhecimento dos sabores sugerem que existam interações entre o sistema gustativo e o nervo trigêmeo (Femiano et al., 2008; Grushka; Sessle, 1988).

Dentre as anormalidades gustativas, podem ser observados erros na identificação de substâncias por $19 \%$ dos doentes, enquanto que apenas $8 \%$ dos controles apresentaram erros, sendo que os sabores salgado e azedo são os de maior dificuldade de reconhecimento (Formaker; Frank, 2000). Outras anormalidades observadas foram ageusia ao sabor amargo e também para o sabor ácido, além do desencadeamento de queimação de forte intensidade pelo sabor picante. Esses dados se correlacionaram com anormalidades de funcionamento da tireóide no grupo de doentes com SAB (Femiano et al., 2006).

Devido às anormalidades sensitivas e gustativas observadas nesses doentes, a SAB tem sido considerada como uma dor de origem neuropática. TSQ além do reflexo córneo-palpebral tem se apresentado alterados nesses doentes (Jääskeläinen et al., 1997; Forssell et al., 2002; Eliav et al., 2007). Esses resultados sugerem anormalidades neurais do tronco cerebral em boa 
parte deles, frequentemente não identificadas na rotina de avaliação devido ao caráter discreto que elas apresentam. Foram observados alodínia ao estímulo quente e limiares somatosensitivos anormais, indicando disfunção de fibras finas. Também foram observadas anormalidades periféricas na análise microscópica de amostras de tecido lingual de doentes, sendo que a densidade de terminações nervosas na SAB apresentou-se diminuída, cuja mensuração correlacionou-se com a dor presente (Lauria et al., 2005). A biópsia superficial da língua pode ser útil no momento do diagnóstico segundo alguns autores (Lauria et al., 2005). Não só as terminações nervosas apresentam-se alteradas nos tecidos orais de doentes com SAB. A circulação periférica desses doentes foi encontrada prejudicada devido à redução no calibre dos capilares em um estudo que utilizou como técnica a vídeo capilaroscopia (Scardina et al., 2008).

Dentre as queixas dos pacientes com diagnóstico de $\mathrm{SAB}$, a xerostomia apresenta importante destaque. Sabe-se que o fluxo salivar, quando em condições normais, garante o equilíbrio necessário a saúde bucal. A saliva evita doenças orais tais como a cárie dentária, doenças periodontais, halitose, e também desconfortos como a própria ardência, a perda do paladar, além de dificuldades na fonação e deglutição (Couto; Lopes, 2010). Se a produção de saliva é reduzida, a mucosa passa a ser insuficientemente umedecida levando a atrofia, ressecamento, displasia, distrofia, passando a apresentar aspecto lustroso, pálido ou avermelhado, levando a sensação de secura que pode ser menos ou mais tolerável pelo 
doente de acordo com seu limiar de sensibilidade e de dor (Navazesh, 1989).

Estudos em laboratório vêm demonstrando que a diminuição salivar é sempre acompanhada por alterações nos eletrólitos salivares e nas imunoproteínas e, sendo assim, parte das anormalidades observadas podem estar relacionadas ao desequilíbrio bioquímico além da diminuição no fluxo salivar em si (Couto; Lopes, 2010). No caso da SAB, os estudos imunológicos de constituição salivar são controversos (Hershkovich; Nagler, 2004), mas há algumas evidências de variações nos níveis de interleucinas 2 e 6 e do fator de necrose tumoral (TNF) (Boras et al., 2006; Simcic et al., 2006). A saliva apresenta um papel importante na transdução de sinais durante a percepção gustativa (Hershkovich; Nagler, 2004), e tanto sua composição bioquímica como seu fluxo podem contribuir para anormalidades sensitivas orais. Entretanto, apesar das queixas de xerostomia, frequentes em indivíduos com SAB, em geral não há evidências de alterações do fluxo salivar ou de sua capacidade de lubrificação nesses indivíduos, quando comparados a pessoas saudáveis ou com ardor bucal por outra etiologia (Tammiala-Salonen; Soderling, 1993; Hershkovich; Nagler, 2004; Soares et al., 2005).

Foi observada uma deficiência de neurocinina A nos doentes quando comparados a controles, o que pode indicar uma ineficiência no sistema dopaminérgico como contribuinte para a fisiopatologia da doença. Não foram evidenciadas anormalidades sorológicas na concentração de substância P e do peptídeo relacionado ao gene da calcitonina (Boras et al., 2010). 
Por outro lado, boa parte desses doentes são idosos, e alterações no fluxo salivar podem estar associadas à idade (Yeh et al., 1998), à doenças sistêmicas ou ao efeito secundário de medicamentos de uso crônico (Navazesh et al., 1996). Apesar de alguns resultados controversos quanto a estes aspectos (Bourdiol et al., 2004; Couto; Lopes, 2010; Moritsuka et al., 2006), o envelhecimento, doenças glandulares, medicamentos, tratamento radioterápico na região de cabeça e pescoço, doenças metabólicas, estresse emocional, dentre outros, podem causar uma disfunção salivar importante e devem ser considerados quando a função salivar pretende ser investigada. Como parâmetro de normalidade na sialometria, um recurso técnico que avalia o volume salivar num período de tempo, os padrões de Pupo et al. (2002) vem sendo amplamente utilizados. O método consiste na comparação do peso de chumaços de algodão antes e após a coleta da saliva, sendo os valores obtidos convertidos em $\mathrm{mL} / \mathrm{min}$. Os valores são considerados normais quando iguais ou maiores a $0,1 \mathrm{~mL} / \mathrm{min}$. 


\section{CASUÍSTICA E MÉTODOS}




\section{$4 \quad$ Casuística e métodos}

\subsection{Casuística}

Foram avaliados 60 doentes consecutivos, diagnosticados com NPH $(n=20)$, NIT $(n=20)$ e SAB $(n=20)$ de acordo com os critérios da IASP (Merskey e Bogduk, 1994). Os doentes estavam em acompanhamento na Equipe de Dor Orofacial (EDOF) e/ou no Ambulatório de Dor Crânio-facial da Divisão de Neurologia do Hospital das Clínicas da Faculdade de Medicina da Universidade de São Paulo (HC-FMUSP). O grupo controle foi composto por indivíduos hígidos, divididos em dois grupos distintos de acordo com a faixa etária, com o objetivo de promover pareamento com os grupos de estudo com relação à idade: Grupo Controle 1 (GC1) (n=30): 18 a 50 e Grupo Controle 2 (GC2) ( $n=30): 51$ a 85 anos de idade.

\subsubsection{Critérios de exclusão}

Grupo de estudo: Foram excluídos os doentes que apresentassem outras síndromes dolorosas faciais associadas, doenças de base com comprometimento de fluxo salivar (ex. síndrome de Sjögren), polineuropatias ou doenças que cursam com ardor bucal (ex. Diabetes mellitus), uso de medicação xerostômica, impossibilidade de responder ao questionário ou aos testes utilizados, cirurgia prévia como tratamento no caso dos doentes com NIT ou outras cirurgias na região crânio-facial; 
Grupo controle: Foram excluídos os indivíduos que apresentassem dor na região orofacial, doenças de base com comprometimento de fluxo salivar (ex. Síndrome de Sjögren), polineuropatias ou doenças que cursam com ardor bucal (ex. Diabetes mellitus), uso de medicação xerostômica, impossibilidade de responder ao questionário ou aos testes utilizados e cirurgia prévia na região crânio-facial.

\subsection{Aspectos éticos}

Todos os indivíduos foram informados quanto aos propósitos desta pesquisa, concordaram em participar do estudo e assinaram o termo de consentimento. Esse trabalho foi aprovado pela CAPPesq (Comissão de Ética para Análise de Projetos de Pesquisa do HCFMUSP) sob o nº 0239/07 e foi realizado através de Auxílio Pesquisa FAPESP (Fundação de Amparo à Pesquisa do Estado de São Paulo) sob o número 2007/04156-4.

\subsection{Métodos}

Os indivíduos participantes deste estudo foram submetidos a um protocolo de TSQ que consistiu de uma avaliação sistemática e padronizada do território de inervação trigeminal bilateralmente (Siqueira et al., 2006b). Os valores obtidos foram anotados em uma ficha padrão desenvolvida pela Equipe de Dor Orofacial (EDOF) (ANEXO A) (Siqueira, 2006c). Todos os 
indivíduos foram avaliados na posição sentada, com a cabeça apoiada em uma superfície plana, e em uma sala silenciosa com proteção acústica nas paredes e portas fechadas. Apenas o indivíduo e o pesquisador estavam na sala. A temperatura média da sala foi de $23^{\circ} \mathrm{C}$. Todos os participantes da pesquisa foram avaliados pelo mesmo pesquisador. Os doentes e os controles foram orientados a manter os olhos fechados durante os exames e se concentrar nos estímulos. O indivíduo deveria informar verbalmente a sensação percebida de imediato, durante aplicação do estímulo. Todos os testes foram realizados nos mesmos pontos previamente determinados, de maneira sequencial, e bilateralmente (Figura 1) (Siqueira et al., 2006a, Alvarez et al., 2007). 

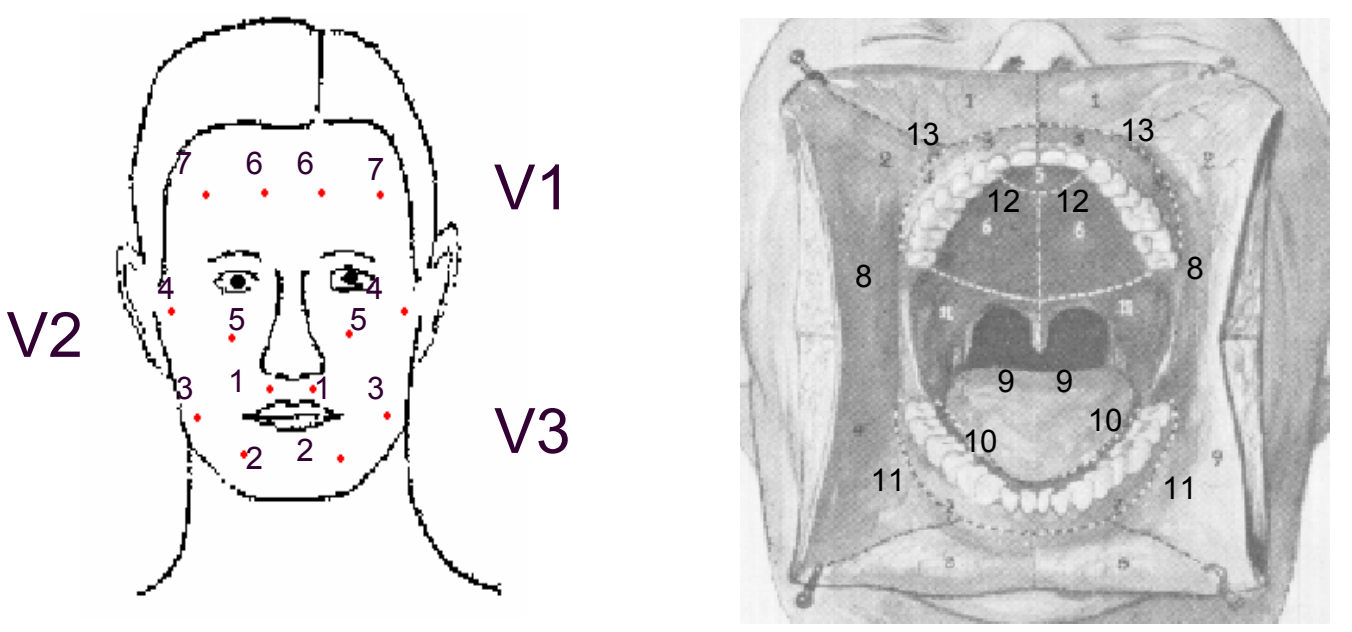

FONTE: Siqueira, 2006

*V1: ramo oftálmico do nervo trigêmeo; V2: ramo maxilar do nervo trigêmeo; V3: ramo mandibular do nervo trigêmeo; **Pontos avaliados: $1: 1 \mathrm{~cm}$ caudalmente em relação a asa do nariz; 2: $1 \mathrm{~cm}$ caudalmente da comissura labial; $3: 1 \mathrm{~cm}$ cranialmente do ângulo da mandíbula; $4: 1 \mathrm{~cm}$ ventralmente à orelha; $5: 1 \mathrm{~cm}$ caudalmente da pálpebra inferior, na linha do centro da pupila; $6: 1 \mathrm{~cm}$ cranialmente da comissura interna do olho; $7: 1 \mathrm{~cm}$ cranialmente da comissura externa do olho; 8: região central da mucosa jugal; $9: 1 \mathrm{~cm}$ da porção média da borda da língua; 10: gengiva lingual dos dentes pré-molares inferiores; 11: gengiva vestibular dos dentes pré-molares inferiores; 12: gengiva palatina dos dentes pré-molares superiores; 13: gengiva vestibular dos dentes pré-molares superiores.

Figura 1 - Pontos de aplicação dos testes sensitivos nos ramos trigeminais 


\subsubsection{Testes sensitivos quantitativos (TSQ)}

Os instrumentos utilizados e o método, na ordem em que foram aplicados, apresentam-se abaixo:

\subsubsection{Detecção de dor - limiares álgicos de superfície}

- Algiômetro de superfície (Micromar®): instrumento manual, que necessita de uma agulha descartável $(15 \times 0,7 \mathrm{~mm})$ acoplada em sua ponta na disposição perpendicular, aplicada verticalmente com pressão em velocidade constante, até a percepção pelo doente e identificação do estímulo (Siqueira, 2006) (Figura 2). Três medidas foram realizadas, em $\mathrm{g} / \mathrm{mm}^{2}$, e as médias e desvios-padrão foram considerados para a análise.

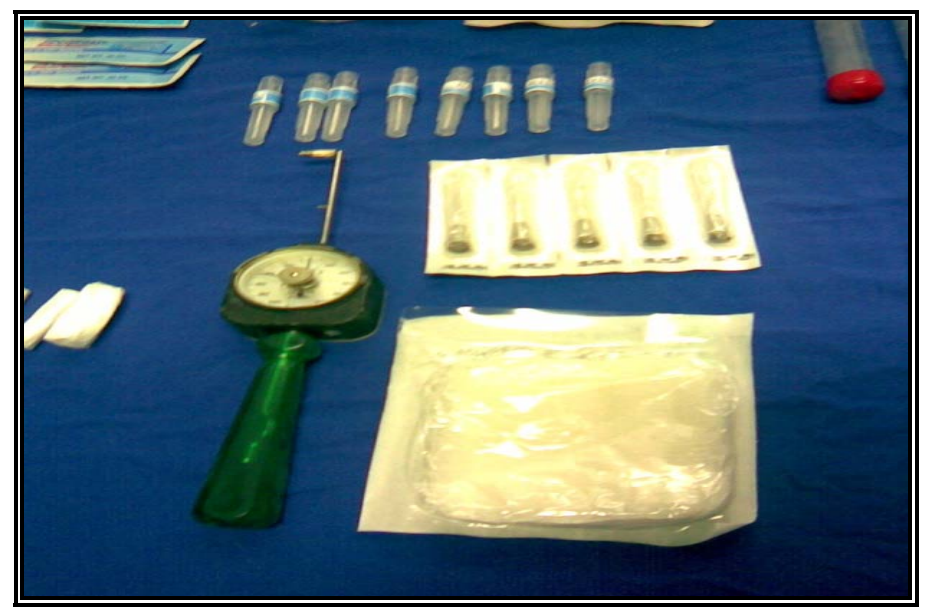

Figura 2 - Algiômetro de superfície - Micromar® 


\subsubsection{Detecção mecânica - percepção tátil superficial}

- Estesiômetro manual (microfilamentos de Von Frey): consiste de um conjunto de filamentos de nylon padronizados com as pontas arredondadas e com diâmetros de tamanho pré-determinado (IITC, Woodland Hills, EUA). Os filamentos foram aplicados verticalmente nos pontos da face prédeterminados, em ordem crescente de diâmetro, até a percepção e identificação do estímulo pelo indivíduo (Siqueira, 2006) (Figura 3). Três mensurações foram realizadas para cada ponto, em $\mathrm{g} / \mathrm{mm}^{2}$, e as médias e os desvios-padrão foram considerados para a análise.

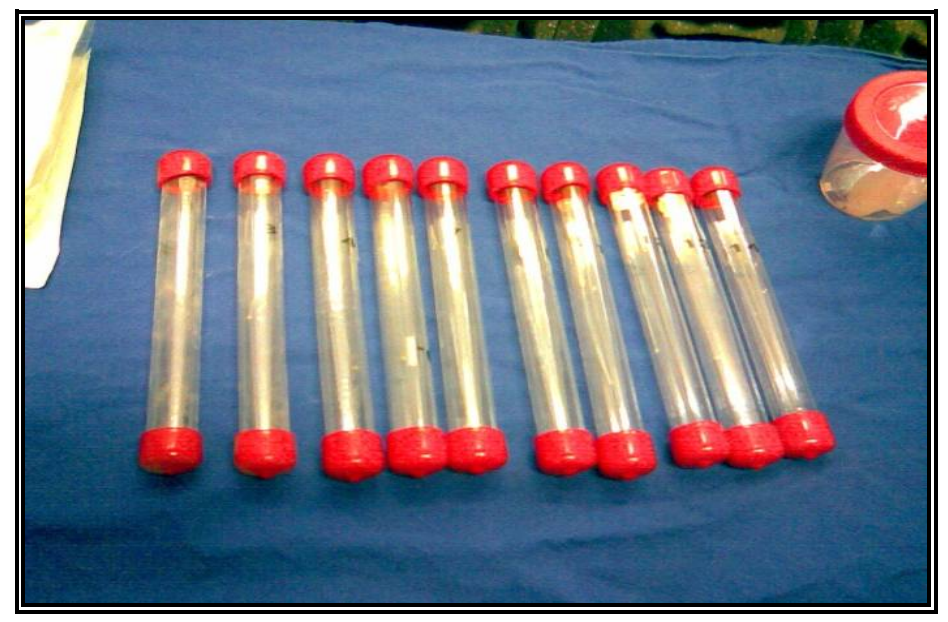

Figura 3 - Estesiômetro manual (microfilamentos de Von Frey) 


\subsubsection{Detecção térmica - percepção das temperaturas (frio e calor)}

- Termoalgiômetro ThermoSensi TS2®: dispositivo de teste térmico eletrônico desenvolvido pela Divisão de Neurocirurgia Funcional do HCFMUSP. O instrumento, de temperatura inicial de $32^{\circ} \mathrm{C}$ e área de contato do termodo de $10 \times 10 \mathrm{~mm}$, foi aplicado verticalmente nos pontos prédeterminados. A temperatura foi gradualmente aumentada (para detecção do estímulo quente) ou reduzida (para detecção do estímulo frio) a uma velocidade constante $\left(1^{\circ} \mathrm{C} / \mathrm{s}\right)$ até que houvesse a percepção e identificação do estímulo pelo indivíduo. Os limites mínimo e máximo do equipamento são de $-4^{\circ} \mathrm{C}$ e $55^{\circ} \mathrm{C}$. A avaliação dos estímulos frios foi realizada antes da avaliação dos estímulos de calor. Para todos os pontos avaliados, foram realizadas três medidas, sendo que as médias e os desvios-padrão foram considerados para a análise (Siqueira, 2006) (Figura 4).

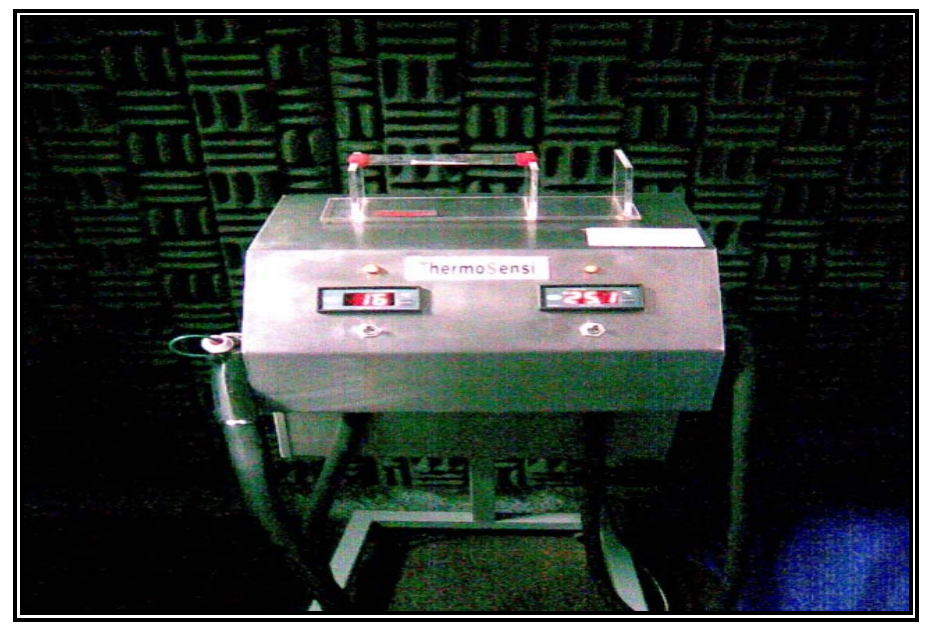

Figura 4 - Termoalgiômetro Thermosensi TS2 


\subsubsection{Avaliação gustativa}

- Limiar gustativo e identificação de substância: Foi aplicada uma gota de cada substância distinta, representando os quatro sabores básicos, na região central da língua, iniciando-se com a menor concentração (Siqueira et al., 2006b) (Figura 5). Após a aplicação de cada gota, o indivíduo deveria durante 15s avaliar o estímulo para percepção e identificação do sabor. Caso não houvesse reconhecimento ou identificação, a próxima concentração era aplicada, até a sua percepção e correta identificação. Foram utilizadas as seguintes substâncias, nas respectivas concentrações molares $\left(\mathrm{mol} / \mathrm{dm}^{3}\right)$ e na seguinte ordem (Kamath et al., 1983; Bartoshuk, 1989; Perros et al., 1996).

o Doce: glicose $\left(0,01 ; 0,032 ; 0,1 ; 0,32 ; 1,0 \mathrm{~mol} / \mathrm{dm}^{3}\right)$

o Salgado: cloreto de sódio $\left(0,01 ; 0,032 ; 0,1 ; 0,32 ; 1,0 \mathrm{~mol} / \mathrm{dm}^{3}\right)$

o Azedo: ácido cítrico $\left(0,01 ; 0,032 ; 0,1 ; 0,32 ; 1,0 \mathrm{~mol} / \mathrm{dm}^{3}\right)$

o Amargo: uréia $\left(0,01 ; 0,032 ; 0,1 ; 0,32 ; 1,0 \mathrm{~mol} / \mathrm{dm}^{3}\right)$

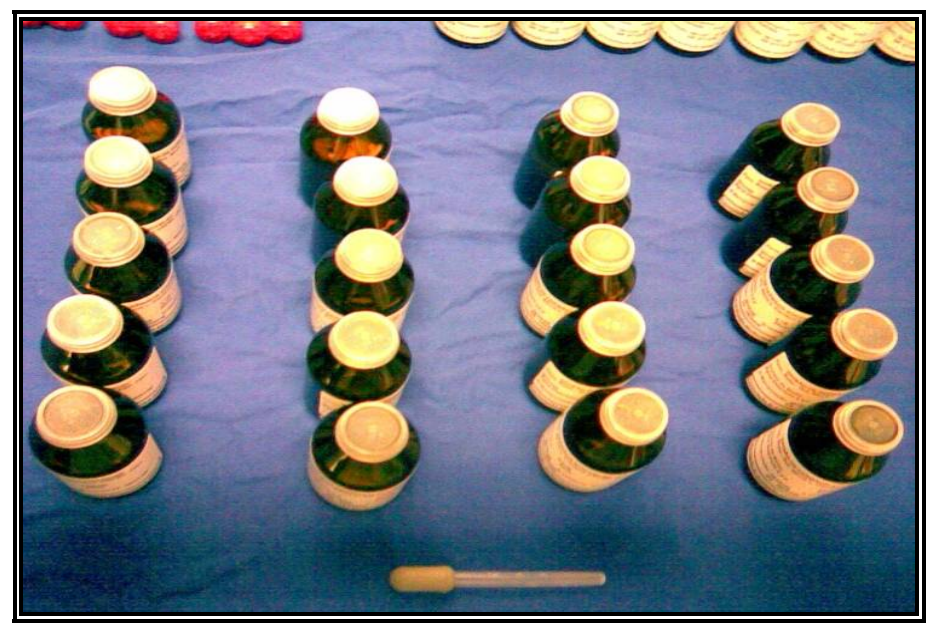

Figura 5 - Frascos das soluções aplicadas nos testes gustativos 


\subsubsection{Avaliação olfativa}

- Limiar olfatório: Foi utilizada a solução de isopropanol 70\% em água deionizada pura e em seis diluições (Figura 6), armazenadas em garrafas de polietileno; o teste iniciou-se com as garrafas de menor diluição, intercalando-se com uma garrafa de água. $\mathrm{O}$ doente deveria escolher a garrafa que apresentasse odor por três vezes. Se houvesse erro, a próxima concentração era apresentada (Cain, 1989; Davidson; Murphy, 1997).

- Identificação de substância: Foram apresentadas aos participantes do estudo, sete substâncias diferentes armazenadas em jarras opacas que não permitissem a identificação visual. As substâncias eram: tabaco, chocolate, canela, café, sabão em pó, papel queimado e vick vaporub®. Uma lista com estas substâncias e outras diferentes foi fornecida de maneira que o doente devesse identificar na lista a substância de odor correspondente.

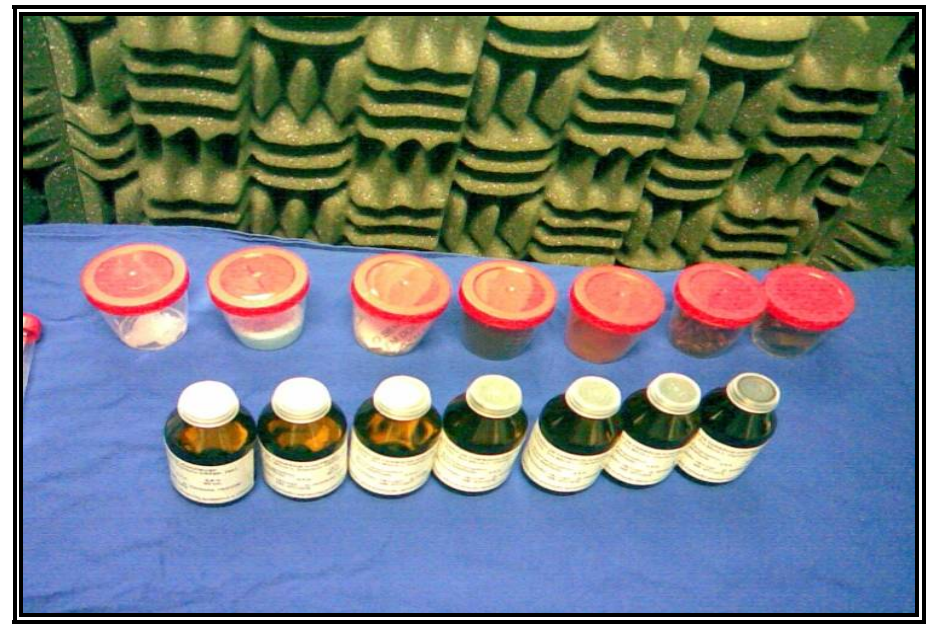

Figura 6 - Frascos das soluções de isopropanol e substâncias aplicadas nos testes olfativos 


\subsubsection{Avaliação salivar quantitativa}

Dois chumaços de algodão foram depositados em um pote plástico do tipo coletor universal $(80 \mathrm{~mL})$ e pesados em uma balança de precisão (Acculab ${ }^{\circledR}$ V1200) (Figura 7). Após a deglutição de toda a saliva pelo doente, os chumaços foram depositados no assoalho bucal, bilateralmente. O algodão permaneceu em repouso por cinco minutos, e o doente foi orientado a não deglutir nesse período. Decorrido o tempo estipulado, o conjunto de chumaços foi removido, devolvido ao pote plástico e pesado novamente. Os valores obtidos pré e pós sialometria foram anotados em $\mathrm{g} / \mathrm{min}$ e convertidos em $\mathrm{mL} / \mathrm{min}$, sendo a diferença considerada como o fluxo salivar do paciente (Pupo et al. 2002). Os indivíduos participantes do estudo foram submetidos aos testes salivares sempre no mesmo horário do dia (por volta das 13 horas), sendo orientados a não ingerir alimentos, não fumar e não mascar chicletes nas 2 horas prévias ao teste para que houvesse uma padronização entre as amostras coletadas.

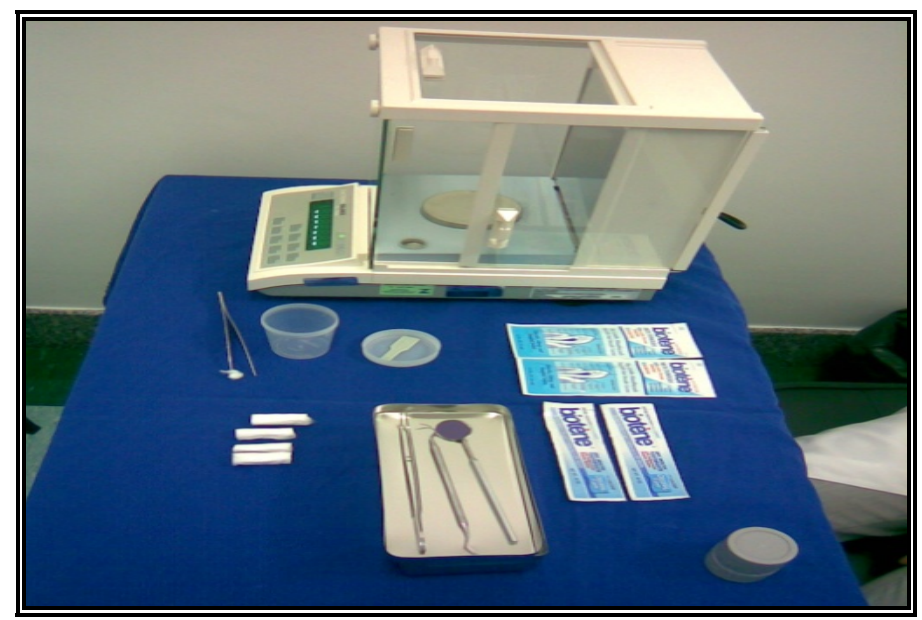

Figura 7 - Avaliação quantitativa de fluxo salivar e Balança Acculab® 


\subsection{Análises dos dados}

Inicialmente, foram calculadas as médias e desvios padrão das análises observadas para cada modalidade sensitiva avaliada. Os dados demográficos dos sujeitos da pesquisa (idade e sexo) foram comparados entre os grupos através dos testes qui-quadrado e ANOVA 1 fator. Os dados de sensibilidade obtidos foram tabulados e submetidos à análise estatística através de testes paramétricos (ANOVA 1 fator e teste de Tukey) e nãoparamétricos (Teste de Kruskall-Wallis e Teste de Dunn). Para a realização dos mesmos foi utilizado o programa SPSS 12 para Windows. O nível de significância utilizado foi de $5 \%$. 
5 RESULTADOS 


\section{$5 \quad$ RESULTADOS}

\subsection{Características gerais da amostra}

Quanto ao sexo, houve $16(80,00 \%)$ mulheres no grupo SAB, 12 $(60,00 \%)$ no grupo NPH e $10(50,00 \%)$ no grupo NIT, sendo que os grupos diferiram estatisticamente. Os grupos controles (GC1 e GC2) não apresentaram diferenças estatísticas quanto ao sexo. Quanto à idade, os grupos NPH e CG2 apresentaram-se semelhantes entre si, porém distintos dos demais grupos desta pesquisa $\left(p=0,0033<0,05_{\mathrm{Fgl}(2 ; 55)=6.37)}(\right.$ Tabela 1$)$.

Tabela 1 - Características demográficas dos grupos de estudo e controle: os controles foram divididos em dois grupos de acordo com a faixa etária $(n=120)$

\begin{tabular}{|c|c|c|c|c|}
\hline \multirow[b]{2}{*}{ Grupos } & \multicolumn{2}{|c|}{ Sexo } & \multirow[b]{2}{*}{$\begin{array}{c}\text { Idade }(\text { anos })^{* *} \\
\text { Média }( \pm D p)\end{array}$} & \multirow[b]{2}{*}{$\begin{array}{c}\text { Comparação / } \\
\text { Correspondência }\end{array}$} \\
\hline & $\begin{array}{c}\mathrm{F} \\
\mathrm{n}(\%)\end{array}$ & $\begin{array}{c}\mathrm{M} \\
\mathrm{n}(\%)\end{array}$ & & \\
\hline $\mathrm{NPH}(n=20)$ & $12(60,00 \%)$ & $8(40,00 \%)$ & $71,33( \pm 8,16)$ & $A$ \\
\hline NIT $(n=20)$ & $10(50,00 \%)$ & $10(50,00 \%)$ & $61,50( \pm 8,97)$ & B \\
\hline SAB $(n=20)$ & $16^{*}(80,00 \%)$ & $4^{*}(20,00 \%)$ & $60,95( \pm 12,21)$ & $B$ \\
\hline GC1 $(n=30)$ & $15(50,00 \%)$ & $15(50,00 \%)$ & $41,60( \pm 6,68)$ & $B$ \\
\hline $\mathrm{GC} 2(n=30)$ & $21^{*}(70,00 \%)$ & $9^{*}(30,00 \%)$ & $70,60( \pm 10,45)$ & $A$ \\
\hline
\end{tabular}

NPH: Neuralgia pós-herpética trigeminal; NIT: Neuralgia idiopática do trigêmeo; SAB: Síndrome da ardência bucal; GC: Grupo controle; F: feminino; M: masculino; * Teste quiquadrado $(p<0,001) ;{ }^{* *}$ ANOVA 1 fator e teste de Tukey $(p=0,33)$ 


\subsection{Testes sensitivos quantitativos (TSQ)}

\subsubsection{Limiares dolorosos de superfície}

Na Tabela 2 podem-se observar as médias $( \pm D p)$ e a análise estatística dos limiares dolorosos de superfície, comparados de acordo com o ramo trigeminal, em cada grupo estudado. O ramo oftálmico (V1) dos grupos NPH e SAB apresentaram limiares álgicos maiores quando comparados aos outros ramos trigeminais dentro do mesmo grupo (Teste ANOVA 1 fator e Teste de Tukey - 5\%).

Tabela 2 - Comparação dos limiares álgicos de superfície entre os ramos trigeminais, nos grupos de estudo $(n=60)$

\begin{tabular}{cccc}
\hline Ramos & NPH $\left(p<0,001^{*}\right)$ & NIT $(p=0,136)$ & SAB $\left(p<0,001^{*}\right)$ \\
\hline V1 & $73,38( \pm 26,85)$ A & $40,25( \pm 28,85) A$ & $31,90( \pm 20,82) A$ \\
V2 & $42,94( \pm 27,14) B$ & $30,35( \pm 12,46) A$ & $18,20( \pm 9,36) B$ \\
V3 & $40,94( \pm 21,87) B$ & $36,20( \pm 17,48) A$ & $22,35( \pm 8,92) B$ \\
\hline
\end{tabular}

NPH: Neuralgia pós-herpética trigeminal; NIT: Neuralgia idiopática do trigêmeo; SAB: Síndrome da ardência bucal; GC: Grupo controle; V1: Ramo oftálmico; V2: Ramo maxilar; V3: Ramo mandibular; * ANOVA 1 fator e teste de Tukey

Na Tabela 3 e na Figura 8 podem-se observar os limiares álgicos de superfície de cada ramo trigeminal, comparados entre os grupos (estudo e controles). O ramo oftálmico no grupo NPH apresentou limiares maiores quando comparados aos outros grupos (Teste ANOVA 1 fator e Teste de 
Tukey - 5\%). Também houve diferenças nos ramos V2 e V3, quando comparados aos controles.

Tabela 3 - Comparação dos limiares álgicos de superfície entre os grupos de estudo e controles $(n=120)$

\begin{tabular}{cccc}
\hline Grupos & $\begin{array}{c}\text { V1 } \\
\left(p=0,00001^{*}\right)\end{array}$ & $\begin{array}{c}\text { V2 } \\
\left(p=0,00001^{*}\right)\end{array}$ & $\begin{array}{c}\text { V3 } \\
\left(p=0,00001^{*}\right)\end{array}$ \\
\hline NPH & $73,38( \pm 26,85) \mathrm{A}$ & $42,94( \pm 27,14) \mathrm{A}$ & $40,94( \pm 21,87) \mathrm{A}$ \\
NIT & $40,25( \pm 28,85) \mathrm{B}$ & $30,35( \pm 12,46) \mathrm{AB}$ & $36,20( \pm 17,48) \mathrm{A}$ \\
SAB & $31,90( \pm 20,82) \mathrm{C}$ & $18,20( \pm 9,36) \mathrm{B}$ & $22,35( \pm 8,92) \mathrm{B}$ \\
GC1 & $23,26( \pm 9,19) \mathrm{C}$ & $23,00( \pm 8,28) \mathrm{B}$ & $25,06( \pm 8,43) \mathrm{B}$ \\
GC2 & $24,73( \pm 8,73) \mathrm{C}$ & $28,06( \pm 12,50) \mathrm{B}$ & $21,86( \pm 7,87) \mathrm{B}$ \\
\hline
\end{tabular}

NPH: Neuralgia pós-herpética trigeminal; NIT: Neuralgia idiopática do trigêmeo; SAB: Síndrome da ardência bucal; GC: Grupo controle; V1: Ramo oftálmico; V2: Ramo maxilar; V3: Ramo mandibular; *estatisticamente significante - ANOVA 1 fator e teste de Tukey

\section{Algiometria}

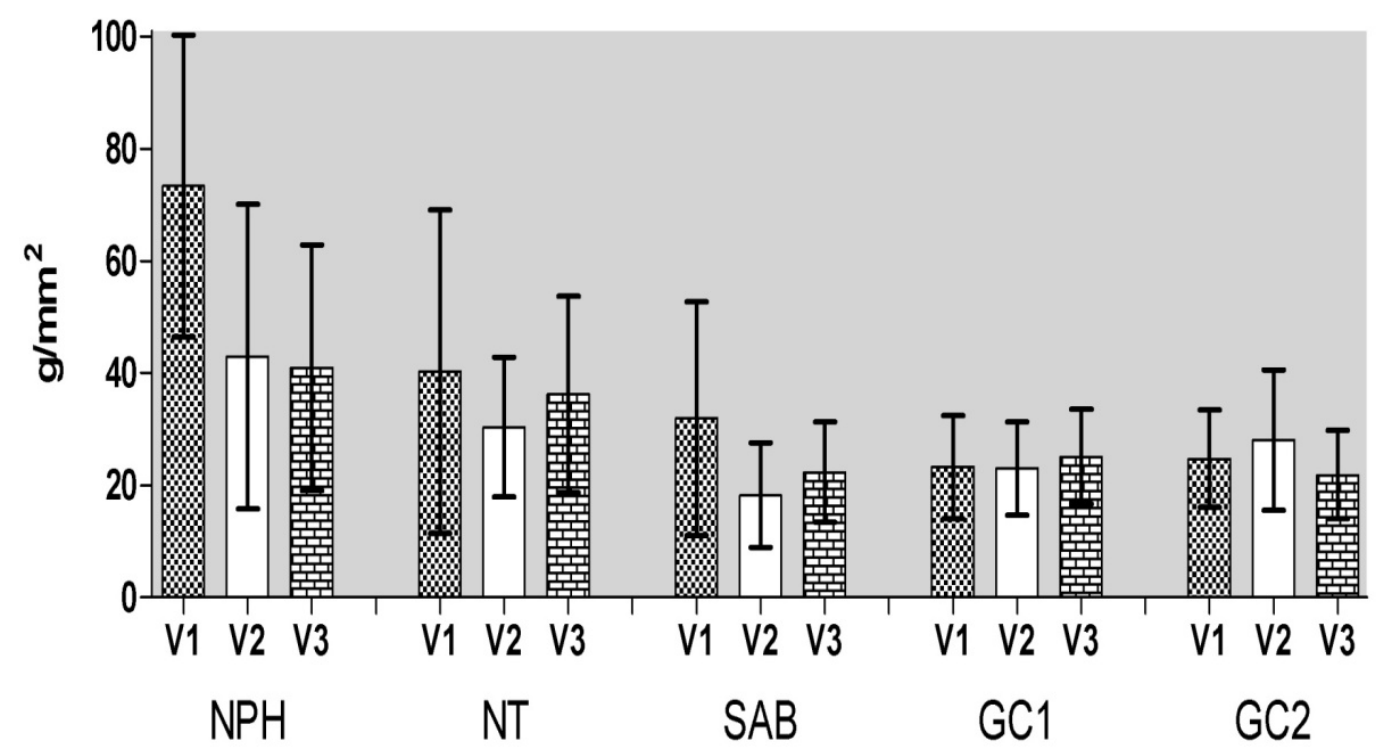

NPH: Neuralgia pós-herpética trigeminal; NIT: Neuralgia idiopática do trigêmeo; SAB: Síndrome da ardência bucal; GC: Grupo controle; V1: Ramo oftálmico; V2: Ramo maxilar; V3: Ramo mandibular

Figura 8 - Comparação dos limiares álgicos de superfície entre os grupos de estudo e controles $(n=120)$ 
Quando comparados os limiares álgicos de superfície na região intraoral, não foram observadas diferenças entre os grupos estudados, em relação aos controles ( $p=0,87)$ (Teste ANOVA 1 fator - 5\%) (Tabela 4).

Tabela 4 - Comparação dos limiares álgicos de superfície entre os grupos de estudo e controles na região intra-oral $(n=120)$

\begin{tabular}{ccc}
\hline Grupos & V2 $\left(p=0,87^{\star}\right)$ & $\mathrm{V} 3\left(p=0,87^{*}\right)$ \\
\hline NPH & $8,89 \pm 19,06$ & $26,10 \pm 23,80$ \\
NIT & $21,50 \pm 22,77$ & $18,00 \pm 18,23$ \\
SAB & $21,00 \pm 19,17$ & $21,00 \pm 19,17$ \\
GC1 & $27,00 \pm 26,59$ & $27,00 \pm 26,59$ \\
GC2 & $28,67 \pm 28,49$ & $28,67 \pm 28,49$ \\
\hline
\end{tabular}

NPH: Neuralgia pós-herpética trigeminal; NIT: Neuralgia idiopática do trigêmeo; SAB: Síndrome da ardência bucal; GC: Grupo controle; V2: ramo maxilar; V3: ramo mandibular; *Não significante estatisticamente - ANOVA 1 fator 
5.2.2 Detecção mecânica (percepção tátil superficial) e detecção de temperaturas (frio e calor)

O grupo NPH apresentou perda de sensibilidade táctil na região do ramo mandibular quando comparado aos outros grupos, o que pode ser observado na Tabela 5. Anormalidades na percepção térmica ao calor e na sensibilidade tátil puderam ser observadas em todos os ramos no grupo SAB. Não houve diferença entre o grupo NIT e os controles nessas modalidades.

Tabela 5 - Comparação dos valores dos testes térmicos e mecânicos, em todos os ramos do trigêmeo, entre os ramos trigeminais e entre os grupos $(n=120)$

\begin{tabular}{|c|c|c|c|c|c|c|c|c|c|}
\hline \multirow[b]{2}{*}{ Grupos } & \multicolumn{3}{|c|}{ Frio } & \multicolumn{3}{|c|}{ Calor } & \multicolumn{3}{|c|}{ Mecânicos/táteis } \\
\hline & $\begin{array}{c}\mathrm{V} 1 \\
p=0,46\end{array}$ & $\begin{array}{c}V 2 \\
p=0,79\end{array}$ & $\begin{array}{c}\text { V3 } \\
p=0,001\end{array}$ & $\begin{array}{c}V 1 \\
p=0,001\end{array}$ & $\begin{array}{c}V 2 \\
p=0,001\end{array}$ & $\begin{array}{c}V 3 \\
p=0,001\end{array}$ & $\begin{array}{c}\mathrm{V} 1 \\
p=0,001\end{array}$ & $\begin{array}{c}\text { V2 } \\
p=0,004\end{array}$ & $\begin{array}{c}\mathrm{V} 3 \\
p=0,001\end{array}$ \\
\hline $\mathrm{NPH}$ & 5 & 4 & $11^{*}$ & $7^{*}$ & $4^{*}$ & $7^{*}$ & 3 & 1 & $10^{*}$ \\
\hline NIT & 3 & 3 & 3 & 2 & 3 & 2 & 4 & 3 & 3 \\
\hline SAB & 5 & 6 & 5 & $5^{*}$ & $6^{*}$ & $6^{*}$ & $8^{*}$ & $8^{*}$ & $8^{*}$ \\
\hline GC1 & 6 & 7 & 7 & 0 & 0 & 0 & 3 & 1 & 4 \\
\hline GC2 & 3 & 8 & 8 & 0 & 0 & 0 & 1 & 1 & 1 \\
\hline
\end{tabular}

NPH: Neuralgia pós-herpética trigeminal; NIT: Neuralgia idiopática do trigêmeo; SAB: Síndrome da ardência bucal; GC: Grupo controle; V1: Ramo oftálmico; V2: Ramo maxilar; V3: Ramo mandibular; *Teste de Kruskall-Wallis e Teste de Dunn 


\subsection{Avaliação gustativa}

Houve diferença entre os grupos estudados, quando comparados aos controles, em três dos quatro sabores básicos (doce, salgado e azedo), porém os grupos não diferiram quanto ao sabor amargo. Enquanto os limiares doces e salgados foram maiores nos doentes do que nos controles, os limiares azedos foram menores nos doentes do que nos controles (Figura 9).

\section{Limiares de Gustação}

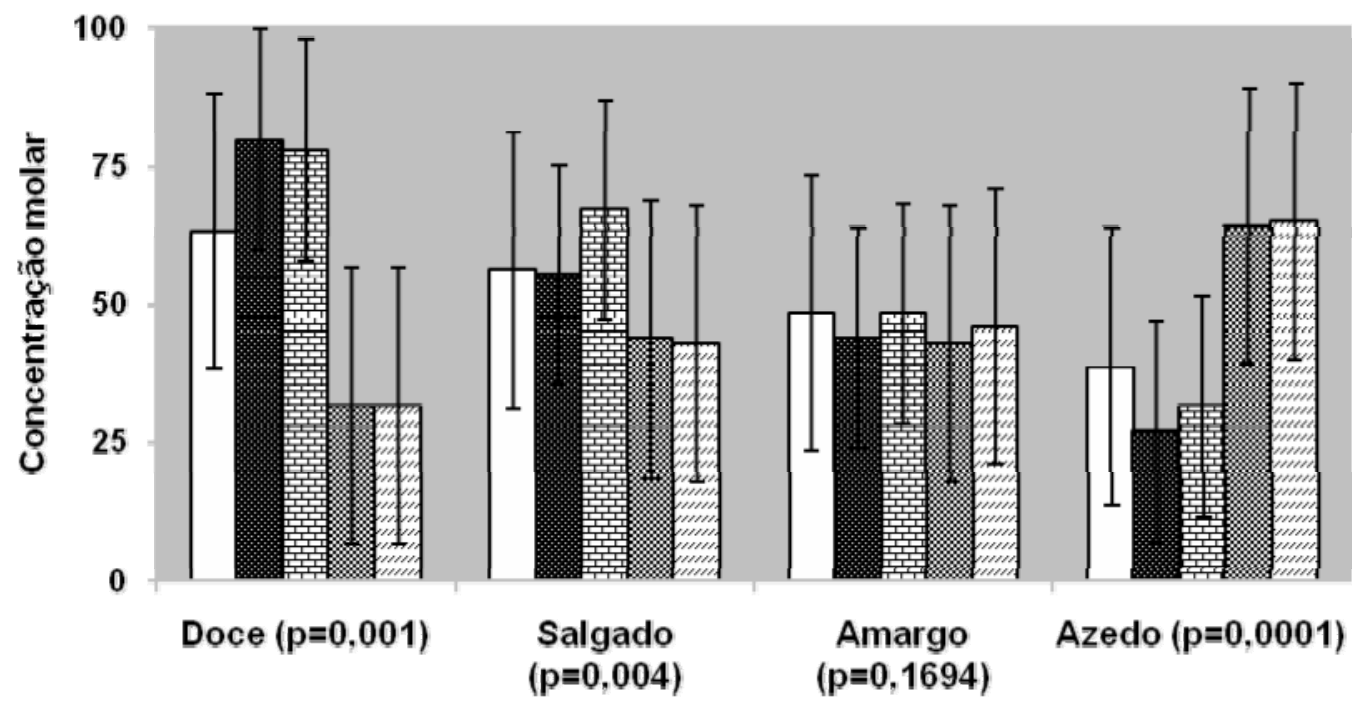

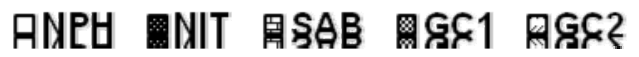

NPH: Neuralgia pós-herpética trigeminal; NIT: Neuralgia idiopática do trigêmeo; SAB: Síndrome da ardência bucal; GC: Grupo controle; * ANOVA 1 fator, Teste de Kruskall-Wallis e Teste de Dunn

Figura 9 - Comparação dos limiares gustativos (doce, salgado, amargo e azedo) entre os grupos de estudo e controles (concentrações molares) $(n=120)$ 


\subsection{Avaliação olfativa}

Os grupos NPH e SAB apresentaram limiares olfativos maiores quando comparados aos controles (Tabela 6). O grupo NIT não apresentou diferença estatisticamente significante.

Tabela 6 - Comparação dos limiares olfativos entre os grupos de estudo e controles $(n=120)$

\begin{tabular}{ccc}
\hline Grupos & Média $( \pm$ desvio padrão $)$ & $\begin{array}{c}\text { Limiar olfativo }(\%) \\
\left(p=0,0389^{*}\right)\end{array}$ \\
\hline NPH & $10,41( \pm 1,56)$ & A \\
NIT & $10,41( \pm 1,56)$ & AB \\
SAB & $12,56( \pm 9,64)$ & A \\
GC1 & $9,90( \pm 0,00)$ & B \\
GC2 & $9,90( \pm 0,00)$ & B \\
\hline
\end{tabular}

NPH: Neuralgia pós-herpética trigeminal; NIT: Neuralgia idiopática do trigêmeo; SAB: Síndrome da ardência bucal; GC: Grupo controle; * estatisticamente significante - Teste de Kruskall-Wallis e Teste de Dunn 
A Figura 10 apresenta os valores de identificação de substâncias no teste olfativo de acordo com o grupo estudado. Podemos observar que os grupos controles apresentaram melhor desempenho no teste do que os grupos de estudo através da análise estatística dos testes Kruskall-Wallis e Dunn.

Avaliação olfativa - Reconhecimento de substâncias

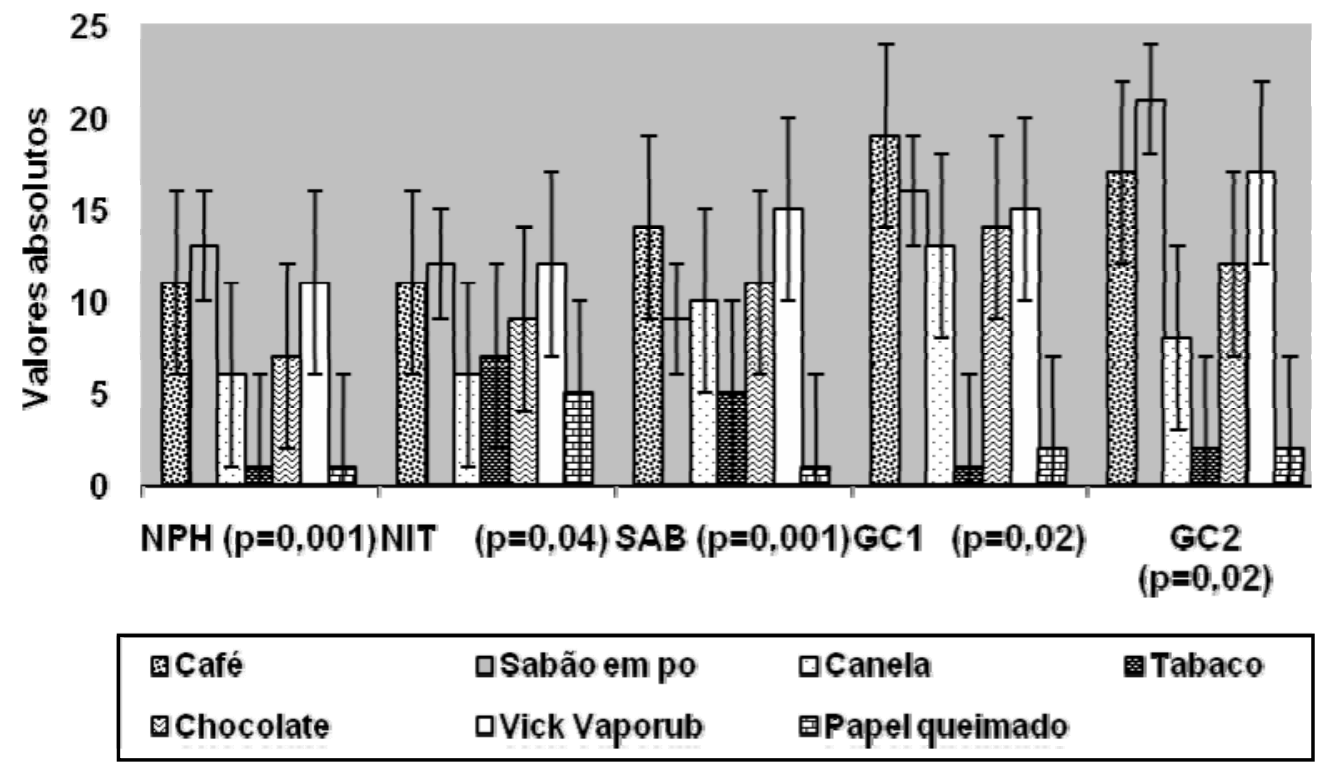

NPH: Neuralgia pós-herpética trigeminal; NIT: Neuralgia idiopática do trigêmeo; SAB: Síndrome da ardência bucal; GC: Grupo controle; *Teste de Kruskall-Wallis e Teste de Dunn

Figura 10 - Comparação entre os grupos de estudo e controles com relação ao teste olfativo de identificação de substância $(n=120)$ 


\subsection{Avaliação salivar quantitativa}

Neste estudo, nenhum doente ou controle apresentou valores de fluxo salivar abaixo da normalidade. Entretanto, os grupos NPH e CG2 apresentaram fluxo salivar semelhante, diferindo estatisticamente dos outros grupos avaliados (Tabela 7).

Tabela 7 - Comparação do fluxo salivar quantitativo entre os grupos de estudo e controles $(\mathrm{mL} / \mathrm{min})(\mathrm{n}=120)$

\begin{tabular}{ccc}
\hline Grupos & $\begin{array}{c}\text { Fluxo salivar }(\mathrm{mL} / \mathrm{min}) \\
\text { Média } \pm \text { desvio padrão }\end{array}$ & $\begin{array}{c}\text { Concordância } \\
\left(\mathrm{p}=0,001^{*}\right)\end{array}$ \\
\hline NPH & $0,1436 \pm 1,32$ & $\mathrm{~A}$ \\
NIT & $0,2881 \pm 0,00$ & $\mathrm{~B}$ \\
SAB & $0,2958 \pm 0,00$ & $\mathrm{~B}$ \\
GC1 & $0,3131 \pm 0,00$ & $\mathrm{~B}$ \\
GC2 & $0,1629 \pm 0,00$ & $\mathrm{~A}$ \\
\hline
\end{tabular}

$\mathrm{NPH}$ : Neuralgia pós-herpética trigeminal; NIT: Neuralgia idiopática do trigêmeo; SAB:

Síndrome da ardência bucal; GC: Grupo Controle; * ANOVA 1 fator e Teste de Tukey 
6 DISCUSSÃO 


\section{DISCUSSÃO}

Os estudos das anormalidades de sensibilidade facial permitem a melhor compreensão fisiopatológica de condições álgicas orofaciais principalmente de caráter neuropático. As evidências de anormalidades em sensibilidades especiais como a olfação e a gustação em doentes com SAB (Grushka; Sessle, 1988) e após o tratamento neurocirúrgico trigeminal em doentes com NIT (Siqueira et al., 2006b) permitiu identificar na clínica evidências das teorias de interação sensitiva amplamente difundidas ao longo do século XX. Nas últimas décadas, devido aos achados de anormalidades gustativas, foi postulada a teoria da desinibição trigeminal a partir de disfunção do nervo corda do tímpano na SAB (Grushka; Sessle, 1988), e anormalidades somestésicas foram encontradas inclusive em condições como a NIT, cujos critérios de diagnóstico necessitam ser revisados uma vez que não incluíam essas alterações dentre os sinais observáveis (Synai et al., 2003; Siqueira et al., 2006a). Esses estudos sugerem que, independentemente da dor neuropática investigada, diferentes graus de comprometimento sensitivo podem ser observados com a cronificação. Sendo assim, os dados aqui obtidos são importantes porque reforçam, através de um método sistematizado e com grupo controle, as modalidades afetadas e o grau de comprometimento sensitivo em doentes com NPH, NIT e SAB, de acordo com os territórios de inervação trigeminal.

Nos doentes aqui investigados, aqueles que apresentavam NPH tiveram o maior comprometimento sensitivo em todas as modalidades e 
principalmente em $\mathrm{V} 1$, mas também em outros ramos trigeminais mesmo na ausência de sinais clínicos da doença. Isso coincide com os nossos achados anteriores (Alvarez et al., 2007), mas é a primeira vez que também evidenciou-se anormalidades gustativas e olfativas na NPH, e propusemos a análise salivar quantitativa de forma a investigar se os achados estavam associados ao fluxo salivar, importante no seu papel de dissolução de substâncias para permitir a transdução sensitiva na cavidade oral (Hershkovich; Nagler, 2004). Nessa amostra, não foram encontradas anormalidades de fluxo salivar na análise pareada quanto a idades, o que indica que os achados devem estar relacionados a outros fatores da própria doença que os indivíduos avaliados apresentam. O comprometimento na região de inervação oftálmica nos indivíduos com NPH era esperado uma vez que essa é a região mais acometida por essa doença (Insinga et al., 2005), mas o acometimento de outras áreas pode dever-se à infecção subclínica e/ou a fenômenos neuroplásticos envolvidos na dor. Também foram estes doentes os únicos que apresentaram anormalidades ao frio (ramo mandibular). O mecanismo neuroplástico deve ser importante nesses achados uma vez que se sabe que o vírus apresenta preferência por fibras mais grossas (Nordenboos, 1959) porém anormalidades de fibras finas, como a sensibilidade térmica alterada e a própria dor, foram encontradas.

Nesse estudo, a SAB foi a segunda doença com mais alterações sensitivas (tácteis, dolorosos, ao calor, gustativas e olfativas). Esses achados reforçam as fortes evidências de mecanismos centrais envolvidos nessa condição incluindo as alterações no reflexo córneo-palpebral 
(Jääskeläinen,1997), que podem ser subsequentes ou causar degeneração em fibras periféricas na língua, o que foi observado em alguns estudos histológicos (Lauria et al., 2005). Sabe-se que a simples lesão de fibras trigeminais em animais altera a palatabilidade e reforça a necessidade de integridade trigeminal para a sensibilidade gustativa (Berridge; Fentress, 1985), sendo que a modulação gustativa depende da variação térmica, ou seja, quanto mais quente melhor a percepção (Bajec; Pickering, 2008). Esses dados, frente aos achados aqui observados, indicam que deve haver comprometimento trigeminal primário e que as anormalidades gustativas e olfativas observadas são secundárias nesses doentes.

Esse estudo também é o primeiro que observa anormalidades olfativas em doentes com NIT sem histórico de cirurgias. As evidências de comprometimento discreto trigeminal (Synai et al., 2003), além de alterações gustativas e olfativas indicam fenômenos centrais envolvidos nesses doentes, que apresentam aparentemente etiologia periférica principal, e indicam a necessidade de revisão das diversas classificações diagnósticas quanto a essa condição, incluindo sinais sensitivos no quadro clínico dessa condição idiopática, e não somente nas neuralgias sintomáticas.

Os limiares gustativos salgados e doces foram maiores nos doentes do que nos controles, porém, em contrapartida, os limiares azedos foram menores nos doentes. As razões para isso não são claras, porém é possível que o envolvimento periférico de vias comuns tanto da sensibilidade gustativa azeda quanto da dor que envolvem os íons ácidos (hidrogênio) podem justificar esse achado de sensibilização de ambas as modalidades. É 
interessante observar que o sabor amargo não apresentou anormalidades nestas amostras, o que pode ser justificado pela mediação do nervo glossofaríngeo (responsável pela somestesia e gustação da região posterior da língua e faringe). É possível que existam caminhos de interação do glossofaríngeo diversos aos do nervo corda do tímpano (ramo do nervo facial). Este parece se correlacionar à somestesia mediada pelo trigêmeo nos dois terços anteriores da língua (Grushka et al., 2006). O nervo facial também media a inervação parassimpática das glândulas salivares (Sobotta, 2000), porém não foram observadas anormalidades salivares nesse estudo. A investigação salivar é importante porque, além do papel da saliva na transdução da sensibilidade da mucosa oral, ela quando alterada pode representar envolvimento do sistema neurovegetativo na dor. Isso pode ser ilustrado pelas repercussões simpáticas na via hipotalâmica por interação central, como nos casos de síndrome complexa de dor regional (Cordon; Lemonica, 2002). É importante lembrar que estes doentes, na grande maioria dos casos, apresentam uso crônico de medicação xerostômica, porém, os que estavam fazendo uso deste tipo de medicação foram excluídos desta amostra. Salienta-se que não foram encontradas anormalidades de fluxo salivar quando os grupos foram comparados com controles pareados quanto a idades. Sendo assim, os indivíduos mais idosos, pertencentes aos grupos de NPH e grupo controle 2, apresentaram o menor fluxo salivar quando comparados aos outros. 


\section{CONCLUSÕES}




\section{CONCLUSÕES}

De acordo com a análise dos dados obtidos, pode-se concluir que:

1. Houve hipoalgesia nos três ramos trigeminais nos doentes com $\mathrm{NPH}$, quando comparados aos outros grupos; hipoestesia táctil foi mais comum nos doentes com SAB, e esteve presente em todo o território de inervação trigeminal; hipoestesia térmica ao calor foi observada em todos os grupos, quando comparados aos controles e hipoestesia térmica ao frio ocorreu somente no ramo mandibular dos doentes com NPH;

2. Gustação (doce e salgado) e olfação apresentaram limiares mais altos nos doentes com SAB e NT; o sabor azedo apresentou limiares reduzidos nos doentes; não houve anormalidades de limiar do sabor amargo.

3. O fluxo salivar apresentou os menores valores nos doentes com NPH e nos indivíduos do grupo controle mais idoso. 
8 ANEXOS 


\section{ANEXOS}

\section{Anexo A - Ficha clínica EDOF-HC}

Nome:

Data:

Grupo: GC1( );GC2( ); NPH( ); SAB( ); NIT( )

Você teve dor na face, nos maxilares, têmpora, na frente do ouvido, ou no ouvido no mês passado? Não 0 Sim 1

Se você teve dor no último mês, como você classificaria a sua dor facial em uma escala de 0 a 10 no presente momento, isto é exatamente agora, onde 0 é "sem dor" e 10 é a "pior dor possível" ?

$\begin{array}{llllllllllll}\text { Sem dor } & 1 & 2 & 3 & 4 & 5 & 6 & 7 & 8 & 9 & 10 & \text { A pior dor possível }\end{array}$

Os seus maxilares estalam quando você abre ou fecha a boca ou quando você mastiga? Não $0 \operatorname{Sim} 1$

Você sente a sua mordida desconfortável ou incomum? Não 0

$\operatorname{Sim} 1$

Seu problema de maxilar tem atrapalhado suas atividades diárias? Comer ( ) Beber ( ) Conversar ( ) outro( )

Seu sono tem sido agitado, perturbado?

$\begin{array}{ccccc}\text { Nem um pouco Um pouco } & \text { Moderadamente } & \text { Muito } & \text { Extremamente } \\ 0 & 1 & 2 & 3 & 4\end{array}$

Mastigação: Queixa espontânea: não( ) $\operatorname{sim}(\quad$ )

Você acha que sua mastigação está normal? não $(） \operatorname{sim}(）$

Se há alteração de mastigação, isto provoca algum incômodo? não ( ) sim ( )

Quantifique este incômodo:

Sem incômodo

Incômodo Intenso

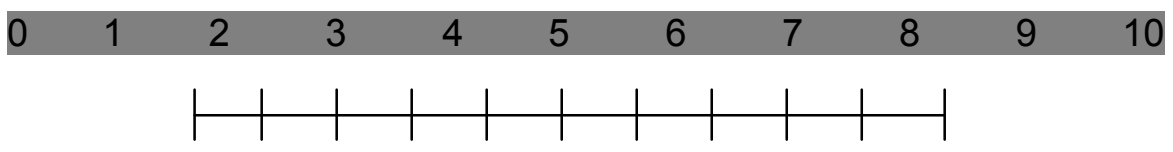

Perda de elementos pela boca:

Saliva: não ( ) eventualmente ( ) frequentemente ( ) $\operatorname{sim}($ ) Alimentos: não ( ) eventualmente ( ) frequentemente ( ) $\operatorname{sim}($ ) 
EXAME FÍSICO

1-Ruídos: ( ) normal ( ) POP ( ) crepitação ( ) D ( )E

Estalo D ( ) IA ( ) MA ( ) FA ( ) IF ( ) MF ( ) FF

Estalo E ( ) IA ( ) MA ( ) FA ( ) IF ( ) MF ( ) FF

2- $A B$ :

mm 3 - Avaliação IOD:

IOE:

Nuca:

4: VAS

5 - Desvios:

\section{AVALIAÇÃO DE SENSIBILIDADE}

\section{Percepção de dormência}

Quão intensa é sua dormência:

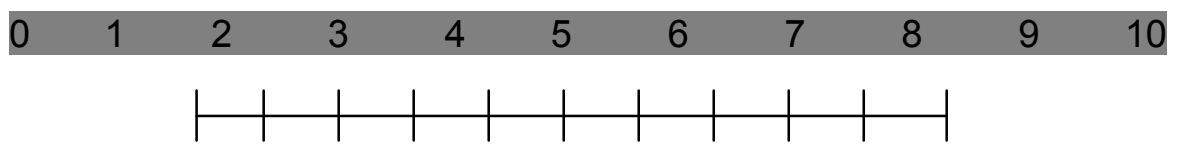

Qual das frases melhor descrevem a ocorrência de dormência (sinalize apenas uma):

( ) Eu constantemente sinto dormência. ( ) Eu eventualmente sinto dormência.

( ) Eu frequentemente sinto dormência. ( ) Eu não sinto dormência.

Informe quão desagradável é sua dormência:

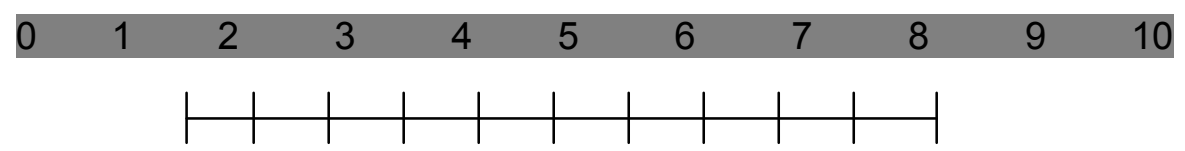

\section{Disestesia}

Quão intensa é sua dor:

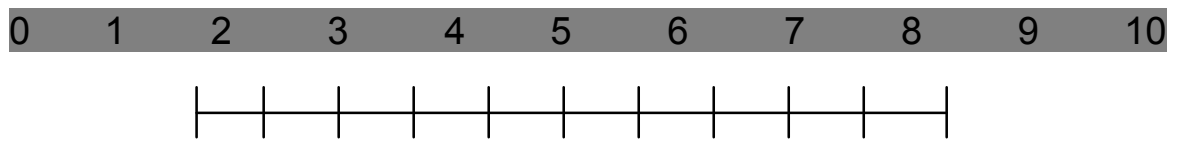


Qual a frequência de sua dor:

não tem dor ( ) frequentemente tem dor ( ) eventualmente tem dor ( ) tem dor constante ( )

\section{$\underline{\text { Sensibilidade da face }}$}
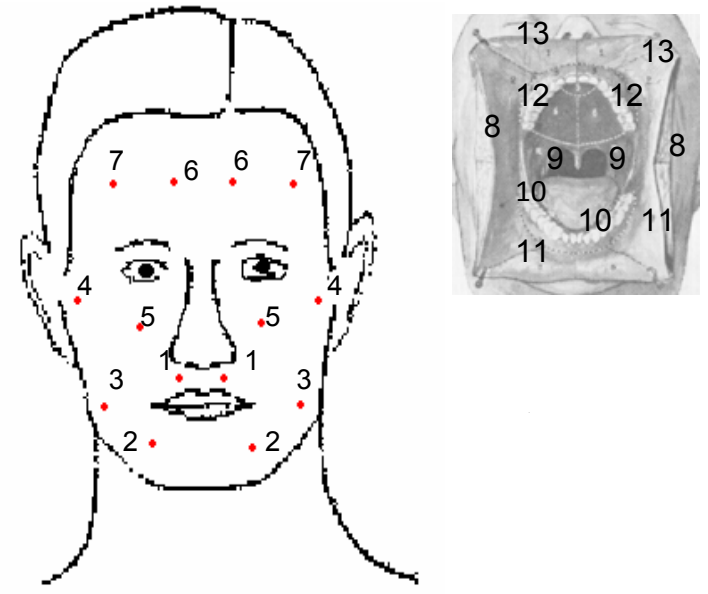

Alfinetes:

Algiômetro (gramas): vide desenho

Termosensibilidade:

Frio

Calor

Vonfrey:

Fumante: não ( ) $\operatorname{sim}($ )

Queixas subjetivas de perda de olfato ou paladar: não ( ) sim ( )

Avaliação Gustativa:

Doce

Salgado

Azedo

Amargo

Avaliação Olfativa:

Avaliação do fluxo salivar: $\mathrm{mL} / \mathrm{min}$ 


\section{REFERÊNCIAS}


Alvarez FK, Siqueira SRDT, Okada M, Teixeira MJ, Siqueira JTT. Evaluation of the sensation in patients with trigeminal post herpetic neuralgia. J Oral Pathol. 2007 Jul; 36(6): 347-50.

Bajec MR, Pickering GJ. Thermal taste, PROP responsiveness, and perception of oral sensations. Physiol Behav. 2008 Nov 28; 95(4):581-90.

Bartoshuk LM. Clinical psychophysics of taste. Gerodontics. 1988 Oct; $4(5): 249-55$.

Bartoshuk L. Clinical evaluation of the sense of taste. Ear Nose Throat J. 1989 Apr; 68(4):331-7.

Bartoshuk LM, Snyder DJ, Grushka M, Berger AM, Duffy VB, Kveton JF. Taste damage: previously unsuspected consequences. Chem Senses. 2005 Jan;30 Suppl 1:i218-9.

Bayer DB, Stenger TG. Trigeminal neuralgia: An overview. Oral Surg Oral Med Oral Pathol. 1979 Nov; 48(5): 393-9.

Bergdahl M, Bergdahl J. Burning mouth syndrome: prevalence and associated factors. J Oral Pathol Med. 1999 Sep; 28(8):350-4.

Bergdahl J, Anneroth G. Burning mouth syndrome: literature review and model for research and management. J Oral Pathol Med. 1993 Nov; 22(10):433-8.

Berridge KC, Fentress JC. Trigeminal-taste interaction in palatability processing. Science. 1985 May 10;228(4700):747-50. 
Boras VV, Brailo V, Lukac J, Kordić D, Blazić-Potocki Z. Salivary interleukin-6 and tumor necrosis factor-alpha in patients with burning mouth syndrome. Oral Dis. 2006 May; 12(3):353-5.

Boras VV, Savage NW, Brailo V, Lukac J, Lukac M, Alajbeg IZ. Salivary and serum levels of substance $P$, neurokinin $A$ and calcitonin gene related peptide in burning mouth syndrome. Med Oral Patol Oral Cir Bucal. 2010 May $1 ; 15(3): \mathrm{e} 427-31$.

Bourdiol P, Mioche L, Monier S. Effect of age on salivary flow obtained under feeding and non-feeding conditions. J Oral Rehabil. 2004 May;31(5):445-52.

Brown GR. Herpes zoster: correlation of age, sex, distribution, neuralgia, and associated disorder. South Med J. 1976 May; 69(5): 576-8.

Buck LB. Olfação e gustação: os sentidos químicos. In: Kandel ER, Schwartz JH, Jessell TM. Princípios da Neurociência. $4^{\mathrm{a}}$ Ed. Rio de Janeiro: Manole. 2003. p.625-47.

Cain WS. Testing olfaction in a clinical setting. Ear Nose Throat J. 1989 Apr; 68(4):316, 322-8.

Cordon FC, Lemonica L. Complex regional pain syndrome: epidemiology, pathophysiology, clinical manifestations, diagnostic tests and therapeutic proposals. Rev Bras Anestesiol. 2002 Sep; 52(5):618-27.

Corey DP, Roper SD (eds). Sensory transduction: society of general physiologists, 45th annual symposium. Marine Biological Laboratory, Woods Hole, Massachusetts, 1992; 5-8 September 1991. New York: Rochefeller Univ. Press.

Couto JAM, Lopes FF. A influência da faixa etária na velocidade do fluxo salivar em adultos. RFO. 2010 maio/ago; 15(2): 135-8. 
Crossman AR, Neary D. Neuranatomia. $2^{\mathrm{a}}$ Ed. Rio de Janeiro: Guanabara Koogan; 2002.

Davidson TM, Murphy C. Rapid clinical evaluation of anosmia. The alcohol sniff test. Arch Otolaryngol Head Neck Surg. 1997 Jun; 123(6):591-4.

Devor M, Amir R, Rappaport ZH. Pathophysiology of trigeminal neuralgia: the ignition hypothesis. Clin J Pain. 2002 Jan-Feb; 18(1):4-13.

Dworkin RH, Portenoy RK. Pain and its persistence in herpes zoster. Pain. 1996 Oct; 67(2-3):241-51.

Eliav E, Kamran B, Schaham R, Czerninski R, Gracely RH, Benoliel R. Evidence of chorda tympani dysfunction in patients with burning mouth syndrome. J Am Dent Assoc. 2007 May; 138(5):628-33.

Felix ER, Widerström-Noga EG. Reliability and validity of quantitative sensory testing in persons with spinal cord injury and neuropathic pain. $J$ Rehabil Res Dev. 2009; 46(1): 69-83.

Femiano F, Lanza A, Buonaiuto C, Gombos F, Cirillo N. Burning mouth disorder (BMD) and taste: a hypothesis. Med Oral Patol Oral Cir Bucal. 2008 Aug 1; 13(8):E470-4.

Femiano F, Gombos F, Esposito V, Nunziata M, Scully C. Burning mouth syndrome (BMS): evaluation of thyroid and taste. Med Oral Patol Oral Cir Bucal. 2006 Jan 1;11(1):E22-5.

Formaker BK, Frank ME. Taste function in patients with oral burning. Chem Senses. 2000 Oct; 25(5):575-81.

Forssell $\mathrm{H}$, Jääskeläinen $\mathrm{S}$, Tenovuo $\mathrm{O}$, Hinkka $\mathrm{S}$. Sensory dysfunction in burning mouth syndrome. Pain. 2002 Sep;99(1-2):41-7. 
Forssell H, Tenovuo O, Silvoniemi P, Jääskeläinen SK. Differences and similarities between atypical facial pain and trigeminal neuropathic pain. Neurology. 2007 Oct 2;69(14):1451-9.

Granot M, Nagler RM. Association between regional idiopathic neuropathy and salivary involvement as the possible mechanism for oral sensory complaints. J Pain. 2005 Sep;6(9):581-7.

Grushka M. Clinical features of burning mouth syndrome. Oral Surg Oral Med Oral Pathol. 1987 Jan;63(1):30-6.

Grushka M, Epstein JB, Gorsky M. Burning mouth syndrome and other oral sensory disorders: a unifying hypothesis. Pain Res Manag. 2003 Fall; 8(3):133-5.

Grushka M, Sessle BJ. Burning mouth syndrome. Dent Clin North Am. 1991 Jan;35(1):171-84.

Grushka M, Sessle B. Taste dysfunction in burning mouth syndrome. Gerodontics. 1988 Oct; 4(5):256-8.

Grushka M, Ching V, Epstein J. Burning mouth syndrome. Adv Otorhinolaryngol. 2006; 63:278-87.

Haanpää M, Laippala P, Nurmikko T. Allodynia and pinprick hypesthesia in acute herpes zoster, and the development of postherpetic neuralgia. J Pain Symptom Manage. 2000 Jul;20(1):50-8.

Hakeberg M, Berggren U, Hägglin C, Ahlqwist M. Reported burning mouth symptoms among middle-aged and elderly women. Eur J Oral Sci. 1997 Dec; 105(6):539-43. 
Hershkovich O, Nagler RM. Biochemical analysis of saliva and taste acuity evaluation in patients with burning mouth syndrome, xerostomia and/or gustatory disturbances. Arch Oral Biol. 2004 Jul; 49(7):515-22.

Insinga RP, Itzler RF, Pelissier JM, Saddier P, Nikas AA. The incidence of herpes zoster in a United States administrative database. J Gen Intern Med. 2005 Aug; 20(8):748-53.

Jääskeläinen SK, Forssell H, Tenovuo O. Abnormalities of the blink reflex in burning mouth syndrome. Pain. 1997 Dec;73(3):455-60.

Jääskeläinen SK, Teerijoki-Oksa T, Forssell H. Neurophysiologic and quantitative sensory testing in the diagnosis of trigeminal neuropathy and neuropathic pain. Pain. 2005 Oct; 117(3):349-57.

Juhl GI, Jensen TS, Norholt SE, Svensson P. Central sensitization phenomena after third molar surgery: a quantitative sensory testing study. Eur J Pain. 2008 Jan;12(1):116-27.

Kamath S, Booth P, Lad TE, Kohrs MB, McGuire WP. Taste thresholds of patients with cancer of the esophagus. Cancer. 1983 Jul 15; 52(2):386-9.

Gardner EP, Martin JH. Coding of sensory information. In: Kandel ER, Schwartz JH, Jessell TM. Princípios da Neurociência. 4ª Ed. Rio de Janeiro: Manole; 2003. p.411-29.

Katusic S, Beard CM, Bergstralh E, Kurland LT. Incidence and clinical features of trigeminal neuralgia, Rochester, Minnesota, 1945-1984. Ann Neurol. 1990 Jan;27(1):89-95.

Koopman JS, Dieleman JP, Huygen FJ, de Mos M, Martin CG, Sturkenboom MC. Incidence of facial pain in the general population. Pain. 2009 Dec $15 ; 147(1-3): 122-7$. 
Kost RG, Straus SE. Postherpetic neuralgia - pathogenesis, treatment, and prevention. N Engl J Med. 1996 Jul 4; 335(1): 32-42.

Lamey PJ. Burning mouth syndrome. Dermatol Clin. 1996 Apr;14(2):339-54.

Lamey PJ, Freeman R, Eddie SA, Pankhurst C, Rees T. Vulnerability and presenting symptoms in burning mouth syndrome. Oral Surg Oral Med Oral Pathol Oral Radiol Endod. 2005 Jan;99(1):48-54.

Lauria G, Majorana A, Borgna M, Lombardi R, Penza P, Padovani A, Sapelli $P$. Trigeminal small-fiber sensory neuropathy causes burning mouth syndrome. Pain. 2005 Jun;115(3):332-7.

Lent R. Os detectores do ambiente: receptores sensoriais e a transdução: primeiros estágios para a percepção. In: Lent R. Cem bilhões de neurônios. Conceitos fundamentais de neurociência. $2^{\mathrm{a}}$ Ed. São Paulo: Artmed; 2003. p.167- 206.

Levin S, Pearsall G, Ruderman RJ. Von Frey's method of measuring pressure sensibility in the hand: an engineering analysis of the WeinsteinSemmes pressure aesthesiometer. J Hand Surg. 1978; 3(3); 211-6.

López-Jornet $\mathrm{P}$, Camacho-Alonso F, Andujar-Mateos $\mathrm{P}$, Sánchez-Siles $\mathrm{M}$, Gómez-Garcia F. Burning mouth syndrome: an update. Med Oral Patol Oral Cir Bucal. 2010 Jul 1;15(4):e562-8.

Melzack R, Wall PD. Pain mechanisms: a new theory. Science. 1965 Nov $19 ; 150(699): 971-9$.

Merskey H, Bogduk N. Classification of chronic pain. $2^{\text {nd }}$ Ed. Seattle: IASP Press; 1994. 
Miller IJ Jr. Taste bud distribution and regional responsiveness on the anterior tongue of the rat. Physiol Behav. 1976 Apr;16(4):439-44.

Moritsuka M, Kitasako Y, Burrow MF, Ikeda M, Tagami J, Nomura S. Quantitative assessment for stimulated saliva flow rate and buffering capacity in relation to different ages. J Dent. 2006 Oct; 34(9): 716-20.

Nasri C, Teixeira MJ, Siqueira JTT. Ardência bucal: avaliação de uma amostra clínica. Rev Simbidor. 2000;1:75-82.

Nasri C, Teixeira MJ, Siqueira JTT. Estudo clínico sobre as características gerais dos pacientes com queixa de ardência bucal. JBA. 2002 out/dez; 2(8): 278-84.

Nasri C, Teixeira MJ, Okada M, Formigoni G, Heir G, Siqueira JT. Burning mouth complaints: clinical characteristics of a Brazilian sample. Clinics. 2007 Oct;62(5):561-6.

Navazesh M. Xerostomia in the aged. Dent Clin North Am. 1989 Jan; 33(1): 75-80.

Navazesh M, Brightman VJ, Podoga JM. Relationship of medical status, medications, and salivary flow rates in adults of different ages. Oral Surg Oral Med Oral Pathol Oral Radiol Endod. 1996 Feb; 81(2): 172-6.

Netto FO, Diniz IM, Grossmann SM, de Abreu MH, do Carmo MA, Aguiar MC. Risk factors in burning mouth syndrome: a case-control study based on patient records. Clin Oral Investig. 2011 Aug; 15(4): 571-5..

Nordenboos W. Problems pertaining to the transmission of nerve impulses which give rise to pain: preliminary statement. Pain Amsterdam: Elsevier, 1959: 6-10. 
Nurmikko T, Bowsher D. Somatosensory findings in postherpetic neuralgia. J Neurol Neurosurg Psychiatry. 1990 Feb; 53(2):135-41.

Penman J. The differential diagnosis and treatment of tic douloureux. Postgrad Med J. 1950 Dec; 26(302): 627-36.

Perros P, MacFarlane TW, Cunsell C, Frier BM. Altered taste sensation in newly-diagnosed NIDDM. Diabetes Care. 1996 Jul; 19(7):768-70.

Petersen KL, Rice FL, Farhadi M, Reda H, Rowbotham MC. Natural history of cutaneous innervation following herpes zoster. Pain. 2010 Jul; 150(1): 7582.

Petersen KL, Rowbotham MC. Natural history of sensory function after herpes zoster. Pain. 2010 Jul; 150(1): 83-92.

Prasad S, Galetta S. Trigeminal neuralgia: historical notes and current concepts. Neurologist. 2009 Mar;15(2):87-94.

Price DD. Psychophysical measurement of normal and abnormal pain processing. In: Boivie J, Hansson P, Lindblom U, Editors. Touch, temperature, and pain in health and disease: mechanisms and assessments. Progress in pain research and management, Volume 3. Seattle: IASP Press, 1994. p.3-25.

Pupo DB, Bussoloti Filho I, Liquidato BM, Korn GP. Proposta de um método prático de sialometria. Rev Bras Otorrinolaringol. 2002; 68(2): 219-22.

Scardina GA, Pisano T, Carini F, Valenza V, Messina P. Burning mouth syndrome: an evaluation of in vivo microcirculation. J Am Dent Assoc. 2008 Jul;139(7):940-6. 
Sherrington C. The integrative action of the nervous system. $2^{\text {nd }}$ ed. New Haven: Yale Univ. Press. 1947.

Simcić D, Pezelj-Ribarić S, Grzić R, Horvat J, Brumini G, Muhvić-Urek M. Detection of salivary interleukin 2 and interleukin 6 in patients with burning mouth syndrome. Mediators Inflamm. 2006;2006(1):54632.

Sinay VJ, Bonamico LH, Dubrovsky A. Subclinical abnormalities in trigeminal neuralgia. Cephalalgia. 2003 Sep; 23(7):541-4.

Siqueira JTT, Teixeira MJ. Dor Orofacial. Diagnóstico, Terapêutica e Qualidade de Vida. Curitiba: Maio; 2001.

Siqueira SRDT. Avaliação funcional mandibular e sensitiva orofacial de doentes com neuralgia trigeminal tratados com compressão do gânglio trigeminal com balão [Dissertação]. São Paulo: Faculdade de Medicina da Universidade de São Paulo; 2006c.

Siqueira SR, Alves B, Malpartida HM, Teixeira MJ, Siqueira JT. Abnormal expression of voltage-gated sodium channels Nav1.7, Nav1.3 and Nav1.8 in trigeminal neuralgia. Neuroscience. 2009 Dec 1;164(2):573-7b.

Siqueira SR, Teixeira MJ, Siqueira JT. Clinical characteristics of patients with trigeminal neuralgia referred to neurosurgery. Eur J Dent. 2009 Jul;3(3):207$12 a$.

Siqueira SR, Teixeira MJ, de Siqueira JT. Severe psychosocial compromise in idiopathic trigeminal neuralgia: case report. Pain Med. 2010 Mar; $11(3): 453-5$.

Siqueira SR, Okada M, Lino AM, Teixeira MJ, Siqueira JT. Proposal for a standardized protocol for the systematic orofacial examination of patients 
with Hereditary Sensory Radicular Neuropathy. Int Endod J. 2006 Nov; 39(11):905-15a.

Siqueira SR, Nóbrega JCM, Teixeira MJ, Siqueira JT. Olfactory threshold increase in trigeminal neuralgia after balloon compression. Clin Neurol Neurosurg. 2006 Dec; 108(8): 721-5b.

Soares MS, Chimenos-Küstner E, Subirá-Pifarrè C, Rodríguez de RiveraCampillo ME, López-López J. Association of burning mouth syndrome with xerostomia and medicines. Med Oral Patol Oral Cir Bucal, 2005 AugOct;10(4):301-8.

Sobotta J. Atlas de anatomia humana. $21^{\text {nd }}$ Ed. Guanabara Koogan: Rio de Janeiro; 2000.

Tammiala-Salonen T, Söderling E. Protein composition, adhesion, and agglutination properties of saliva in burning mouth syndrome. Scand J Dent Res, 1993 Aug;101(4):215-8.

Teixeira MJ. A lesão por radiofrequência e a descompressão neurovascular para o tratamento da neuralgia do trigêmeo [dissertação]. São Paulo: Faculdade de Medicina da Universidade de São Paulo; 1984.

Teixeira MJ. Tratamento da neuralgia do trigêmeo. In: Pré-Congresso. São Paulo: $4^{\circ}$ Congresso Brasileiro de Neurocirurgia, 1998. 3: 18.25-36.

Teixeira MJ, Okada M. Neuralgia pós-herpética. Rev Med. 1999; 78:140-49.

Tidwell E, Hutson B, Burkhart N, Gutmann JL, Ellis CD. Herpes zoster of the trigeminal nerve third branch: a case report and review of the literature. Int Endod J. 1999 Jan;32(1):61-6. 
Thyregod HG, Rowbotham MC, Peters M, Possehn J, Berro M, Petersen KL. Natural history of pain following herpes zoster. Pain. 2007 Mar; 128(1-2):14856.

Van Der Waal I. Burning mouth syndrome. Ned Tijdschr Tandheelkd. 2001 Jun;108(6):237-41.

Van Kleef M, Van Genderen WE, Narouze S, Nurmikko TJ, Van Zundert J, Geurts JW, et al. 1. Trigeminal neuralgia. Pain Pract. 2009 Jul-Aug; 9(4):2529.

Watson CPN, Morshead C, Van Der Kooy D, Deck J, Evans RJ. Postherpectic neuralgia: post-mortem analysis of a case. Pain. 1988 Aug; 34(2): 129-38.

Watson CP, Deck JH, Morshead C, Van der Kooy D, Evans RJ. Postherpetic neuralgia: futher post-mortem studies of cases with and without pain. Pain. 1991 Feb; 44(2):105-17.

Yeh CK, Johnson DA, Dodds MW. Impact of aging on human salivary gland function: a community-based study. Aging (Milano). 1998 Oct;10(5):421-8.

Zacks SL, Elliott FA, Langfitt TW. Herpectic neuritis: a light and electron microscopic study. Neurology. 1964 Aug; 14: 744-50. 


\section{APÊNDICES}




\section{Apêndice 1 - Parecer do Comitê de Ética}

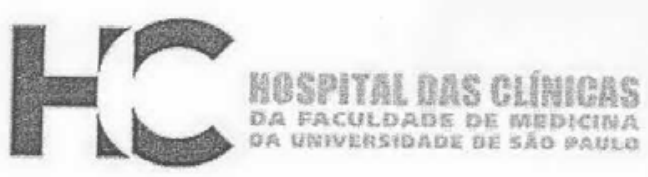

\section{APROVAÇÃO}

A Comissão de Ética para Análise de Projetos de Pesquisa - CAPPesq da Diretoria Clínica do Hospital das Clínicas e da Faculdade de Medicina da Universidade de São Paulo, em sessão de 20.06.07, APROVOU o Protocolo de Pesquisa $n^{\circ}$ 0239/07, intitulado: "AVALIAÇÃO SENSORIAL GUSTATIVA E OLFATIVA EM DOENTES COM NEUROLGIA PÓS HERPÉTICA E SÍNDROME DA ARDÊNCIA BUCAL", apresentado pelo DEPARTAMENTO DE NEUROLOGIA, inclusive o Termo de Consentimento Livre e Esclarecido.

Cabe ao pesquisador elaborar e apresentar à CAPPesq, os relatórios parciais e final sobre a pesquisa (Resolução do Conselho Nacional de Saúde n 196, de 10.10.1996, inciso IX. 2, letra. "c")

Pesquisadores Responsáveis: Dr. Manoel Jacobsen Teixeira, Dr. José Tadeu Tesseroli de Siqueira, $\mathrm{Dr}^{\mathrm{a}}$. Silvia Regina Dowgan Tesseroli de Siqueira

Pesquisador (a) Executante: Mariana Siviero

CAPPesq, 20 de junho de 2007.

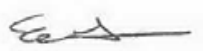

PROF. DR. EDUARDO MASSAD

Presidente da Comissão de Ética para Análise de Projetos de Pesquisa 


\title{
Apêndice 2 - Publicações Científicas
}

\author{
ORAL IDISEASES \\ Oral Diseases (2010) 16, 482-487. dot:10.1111/4.1601-0825.2010.01660x \\ O 2010 John Wiley \& Sons A \\ hetcp://mww.blachwellmunksgard.com

\section{ORIGINAL ARTICLE}

\section{Somesthetic, gustatory, olfactory function and salivary flow in patients with neuropathic trigeminal pain} \\ M Siviero $^{1}$, MJ Teixeira ${ }^{2}$, JTT de Siqueira ${ }^{2,3}$, SRDT Siqueira $^{2,4}$ \\ 'Orofacial Pain Team, Department of Neurology, Medical School, University of Sao Paulo, Sao Paulo, Brazil: \\ ${ }^{2}$ Department of Neurology, Medical School, University of Sao Paulo. Sao Paulo, Brazil, ${ }^{3}$ Dentistry Division, Hospital das Clinicas. \\ Medical School, University of Sao Paulo, Sao Paulo, Brazil; ${ }^{4}$ School of Arts, Science and Humanities, University of São Paulo, Sao \\ Paulo, Brazil
}

OBJECTIVES: To determine somesthetic, olfactory, gustative and salivary abnormalities in patients with burning mouth syndrome (BMS), idiopathic trigeminal neuralgia (ITN) and trigeminal postherpetic neuralgia (PHN).

SUBJECTS AND METHODS: Twenty patients from each group (BMS, ITN, PHN) and 60 healthy controls were evaluated with a systematized quantitative approach of thermal (cold and warm), mechanical, pain, gustation, olfaction and salivary flow; data were analyzed with ANOVA, Tukey, Kruskal-Wallis and Dunn tests with a level of significance of $\mathbf{5 \%}$.

RESULTS: There were no salivary differences among the groups with matched ages; the cold perception was abnormal only at the mandibular branch of PHN $(P=0.001)$ and warm was abnormal in all trigeminal branches of PHN and BMS; mechanical sensitivity was altered at the mandibular branch of PHN and in all trigeminal branches of BMS. The salty, sweet and olfactory thresholds were higher in all studied groups; the sour threshold was lower and there were no differences of bitter.

CONCLUSION: All groups showed abnormal thresholds of gustation and olfaction; somesthetic findings were discrete in ITN and more common in PHN and BMS; central mechanisms of balance of sensorial inputs might be underlying these observations.

Oral Diseoses (2010) 16, 482-487

Keywords: sensorial interaction; facial sensibility; orofacial pain; trigeminal nerve; taste; olfactory threshold; gustation; neuropathic pain; quantitative sensory testing

Correspondence: Silvia RDT Siqueira, Rua Carlos Weber, 1319 P164 V Leopoldina, 05303-000 São Paulo-SP-Brazil. Tel: 5511 91842878, Fax: 551129730642 , E-mail: silviadowgan@ 9 hotmail.com
Received 28 October 2009; accepted 29 November 2009

\section{Introduction}

Trigeminal postherpetic neuralgia (PHN), idiopathic trigeminal neuralgia (ITN) and burning mouth syndrome (BMS) are the most common neuropathic pain syndromes that affect the facial region. Neuropathic pain is associated to abnormalities in the peripheral (PNS) and/or central nervous system (CNS) (Kost and Straus, 1996), such as neuroplastic changes, cellular death, facilitation and long term potentiation of synapses, which may cause sensorial abnormalities (Watson et al, 1991). At the trigeminal area, the taste and smell perception are involved in the sensorial input of the oral and nasal cavity.

Besides somesthetic abnormalities, altered gustation has been identified in trigeminal neuropathic pain (Grushka and Sessle, 1988; Grushka et al, 2003; Femiano et al, 2008). However, in the current scientific literature, it was not possible to find controlled comparative studies with complete sensorial evaluation of these patients including the olfaction and salivary flow. which are important parts of taste perception. These findings can essentially contribute to the understanding of physiopathological mechanisms of these diseases. Thus, the objective of this study was to determine the somesthetic, olfactory, gustative and salivary flow abnormalities in patients with BMS, ITN and PHN compared with controls.

\section{Material and methods}

This research was approved by the Ethics Committee of Hospital das Clinicas, Medical School, University of Sao Paulo (HC-FMUSP), and all patients signed the informed consent. Sixty $(n=60)$ consecutive patients diagnosed as BMS $(n=20)$, ITN $(n=20)$ and PHN $(n=20)$ according to the International Association for the Study of Pain (IASP) criteria (Merskey and Bogduk, 1994) were evaluated at the Orofacial Pain Team of HC-FMUSP between August 2007 and January 2008 and compared with 60 healthy subjects divided into two groups according to the ages: CG1 $(n=30)$ : $18-50$ 


\section{RAPID COMMUNICATION}

\section{Central mechanisms in burning mouth syndrome involving the olfactory nerve: a preliminary study}

Mariana Siviero,' Manoel Jacobsen Teixeira," José Tadeu Tesseroli de Siqueira,"' Sílvia Regina Dowgan Tesseroli de Siqueira ${ }^{\text {IV }}$

'Orofacial Pain Team, Faculdade de Medicina da Universidade de Sao Paulo, Brazil, "Neurology Department, Faculdade de Medicina da Universidade de Sao Paulo, Brazil. "'Head of the Orofacial Pain Team, Dentistry Division, Faculdade de Medicina da Universidade de Sao Paulo, Brazil. "School of Arts, Science and Humanities, Universidade de Sao Paulo, Brazil.

Email: silviadowgan@hotmail.com

Tel.: 551191842878

\section{INTRODUCTION}

Burning mouth syndrome (BMS) is characterized by a continuous sensation of burning or heat in the oral cavity, mainly on the tongue, palate and/or gingiva ${ }^{1-3}$, in the absence of a primary cause ${ }^{4-5}$. Systemic diseases, such as diabetes mellitus or anemia, must be ruled out ${ }^{3}$. It is most common among postmenopausal women and causes intense discomfort and suffering.

There is no defined etiology for BMS other than precipitating causative factors, and it is still considered idiopathic. One of the most widely accepted theories is that the partial or total loss of chorda tympani (facial) nerve function disinhibits the trigeminal nerve, resulting in pain along trigeminal pathways, as both taste and pain systems are regulated by interneurons of the central nervous system (CNS) ${ }^{6-8}$. This theory is based on evidence of neuropathic mechanisms ${ }^{9-10}$, including the loss of small fibers in oral tissues ${ }^{11}$, salivary and somatosensory abnormalities ${ }^{8-10,12-14}$ reduced corneal reflexes 15 , and peripheral nerve degeneration 11-16. Despite the known interaction between smell and taste ${ }^{17}$, we found no studies that investigated it in relation to BMS.

Thus, the objective of this preliminary study was to determine tactile, pain, thermal, gustative and olfactory thresholds in a group of patients with BMS as compared with controls.

\section{METHODS}

This research was approved by the Ethics Committee of Hospital das Clinicas, Medical School, University of Sao Paulo (HC-FMUSP), and all patients provided informed consent. Twenty consecutive patients with BMS, diagnosed according to the International Association for the Study of Pain (IASP) criteria ${ }^{18}$, were evaluated by the HC-FMUSP orofacial pain team between August 2007 and January 2008 and then compared with 30 normal subjects. All patients had BMS for more than 3 years and had no oral infections or

Copyright 02011 CuNICS - This is an Open Access article distributed unde the terms of the Creative Commons Attribution Non-Commercial License (http:/ creativecommons.org/licenses/by-nc/3.0/ which permits unrestricted non commercial use, distribution, and reproduction in any medium, provided the original work is properly cited. other lesions and no diseases included in the exclusion criteria.

Inclusion criteria: The study included 20 patients newly diagnosed with BMS who had not begun pharmacologica treatment and 30 healthy controls with no complaint of facial or intraoral pain within the last 6 months who were consecutively selected from patients receiving dental treatment at the Dentistry Division of the hospital.

Exclusion criteria (for patients and controls): Exclusion criteria included Sjögren syndrome, rheumatological diseases (i.e., fibromyalgia and rheumatoid arthritis), diabetes, anemia, hyper- or hypothyroidism, generalized pain, and history of surgery in the facial/oral region. The patients and controls underwent a systematized evaluation by the hospital's general physician to investigate the presence of systemic diseases. In addition to the clinical exam, a hematological evaluation of thyroid hormones, glycemia rheumatoid factors, including reactive $\mathrm{C}$ protein and hemosedimentation velocity, and hemogram values was performed.

All subjects underwent a standardized superficial facial sensibility protocol applied to distinct areas of the face (bilateral trigeminal branches) and oral mucosa (superior and inferior arches) ${ }^{19}$ in the following order.

(1) Thermal sensibility (using an electrical device designed at the Functional Neurosurgery Division of HC-FMUSP) at a temperature range between $0^{\circ} \mathrm{C}$ and $50^{\circ} \mathrm{C}$.

(2) Mechanical/tactile sensibility (using microfilaments from von Frey) ranging from $0.1 \mathrm{~g} / \mathrm{mm} 2$ to $10.0 \mathrm{~g} / \mathrm{mm} 2$.

(3) Pain sensibility/superficial algometry (using Micromar ${ }^{\$}$, Diadema, São Paulo, Brazil).

Each thermal and mechanical stimulus was applied three times, and the threshold was established when the subject recognized at least two of the three applications. If this did not happen, the next stimulus in crescent order would be applied to avoid a tolerance effect. Algometry was performed with a superficial device and a disposable $0.7 \times 15-\mathrm{mm}$ needle. The ophthalmic branch (V1) was evaluated $1 \mathrm{~cm}$ above the eyebrow, and the maxillary branch (V2) was evaluated $1 \mathrm{~cm}$ to the side of the nose wing. Finally, the mandibular branch (V3) was evaluated $1 \mathrm{~cm}$ below the angle of the lips. 


\title{
Apêndice 4 - Publicações Científicas
}

Clinical Neurology and Neurosurgery 113 (2011) 268-271

Contents lists available at ScienceDirect

Clinical Neurology and Neurosurgery

journal homepage: www.elsevier.com/locate/clineuro

\section{Facial sensibility of patients with trigeminal neuralgias ${ }^{\text {th }}$}

Mariana Siviero ${ }^{b}$, Fábio Kurogi Alvarez ${ }^{b}$, Massako Okada ${ }^{c}$, Manoel Jacobsen Teixeira ${ }^{d}$, José Tadeu Tesseroli de Siqueira ${ }^{e}$, Sílvia Regina Dowgan Tesseroli de Siqueira a,f, *

-Av Arlindo Bettio, 1000 Ermelindo Matarazzo CEP: 03828-000, Såo Paulo, SP, Brazil

- Orofacial Pain Team, Medical School, University of Säo Paulo, Brazil

cInterdisciplinary Pain Center, Neurology Department, Medical School, University of Søo Paulo, Brazil

Neurology Department, Medical School, University of São Paulo, Brazil

"Orofacial Pain Team, Dentistry Division, Medical School, University of São Paulo, Brazil

'School of Arts, Science and Humanities, University of Săo Paulo, Brazil

A R T I L E I N FO

Article history:

Received 29 July 2009

Accepted 17 November 2010

Available online 10 December 2010

Keywords:

Trigeminal neuralgia

Postherpetic neuralgia

Facial sensibility

Orofacial pain
Trigeminal nerve

\begin{abstract}
A B S T R A C T
Objectives: Idiopathic trigeminal neuralgia (ITN) is an excruciating shock-like paroxysmal pain restricted to the trigeminal area of innervation, with discrete loss of sensibility (thermal, tactile and painful). Trigeminal postherpetic neuralgia (PHN) is a neuropathic pain at the trigeminal territory that persists after Herpes zoster infection, which also is associated to sensorial compromise. The objective of this study was to evaluate the somesthetic facial sensibility (pain, thermal and tactile) and to compare the findings between PHN and ITN.

Methods: 18 patients with PHN and 26 patients with ITN were diagnosed by the IASP criteria. They were evaluated with a systematic approach, which included mechanical, thermal (cold and warm) and painful stimuli.

Results: We found statistical significance at the ophthalmic branch of PHN in pain $(p=0.001)$, tactile $(p=0.002)$, cold $(p=0.016)$ and warm $(p=0.013)$; in ITN, the maxillary branch had higher threshold with $(p=0.002)$, cold $(p=0.016)$ and warm $(p=0.013)$; in ITN, the maxillary branch
pinpricks $(p=0.016)$ and the mandibular branch had higher tactile threshold.

Conclusions: The trigeminal area affected by the disease had the higher sensorial losses (ophthalmic branch in PHN and maxillary/mandibular branches in ITN). PHN patients had losses in large and small fibers; therefore, ITN patients had the losses mostly in large fibers, which support different peripheral neural mechanisms for these neuropathic diseases.
\end{abstract}

O 2010 Elsevier B.V. All rights reserved.

\section{Introduction}

Trigeminal postherpetic neuralgia ( $\mathrm{PHN}$ ) and idiopathic trigeminal neuralgia (ITN) are neuropathic pain syndromes that affect the face. Pain is in general attributed to demyelination, wallerian degeneration and/or sclerosis of peripheral (PNS) and/or central nervous system (CNS) [1]. This includes central abnormalities as atrophia, cellular death and neuroplastic phenomena, which clinically represent atypical sensorial manifestations [2].

$\mathrm{PHN}$ is described as chronic pain that persists for more than 3 months after the healing of an acute infection of varicela zoster virus; it affects the trigeminal nerve in $15-20 \%$ of the cases and the ophthalmic branch (V1) is the most affected [3]. Pain is continuous and limited to the trigeminal branch previously affected

\footnotetext{
मे Financial support: FAPESP - Foundation of Research of the State of Såo Paulo,

FAPESP. 2007/04156-4.
- Corresponding author at: Rua Carlos Weber, 1319 P164V Leopoldina, 05303-000 São Paulo, SP. Brazil. Tel.: +55 1191842878.
}

E-mail address: silviadowganehotmail.com (S.R.D.T. de Siqueira). by the infection. It is usually described as burning, but shock-like pain may occur. It is common to observe allodynia in these patients. The characteristics of pain determine pharmacological treatment. It shows in general sensitive abnormalities as paresthesia, hypoesthesia and sensorial deficit at the affected area, and findings that are more evident depending on pain intensity [4,5].

ITN is the most debilitating facial neuralgia known. It is characterized as chronic, paroxysmal, shock-like pain with variable frequency, commonly associated to the vascular compression of the trigeminal root at the entry zone. Pain is distributed in one or more trigeminal branches. It is often associated to a trigger zone. and the light touch at this area may cause the pain. Because of it, when in crises, patients avoid contact with their faces, and eating or talking become difficult tasks due to pan triggering. Imaging exams are important in order to exclude primary causes that would characterize symptomatic trigeminal neuralgia. It usually affects intra and peri-oral areas, and rarely, V1 [6]. Treatment includes anticonvulsants, and carbamazepine is the drug of choice. However, many patients need neurosurgery to alleviate their pain. Sensory deficit are not observed in these cases, but some recent studies have shown that discrete sensitive abnormalities can be found at the territory of 